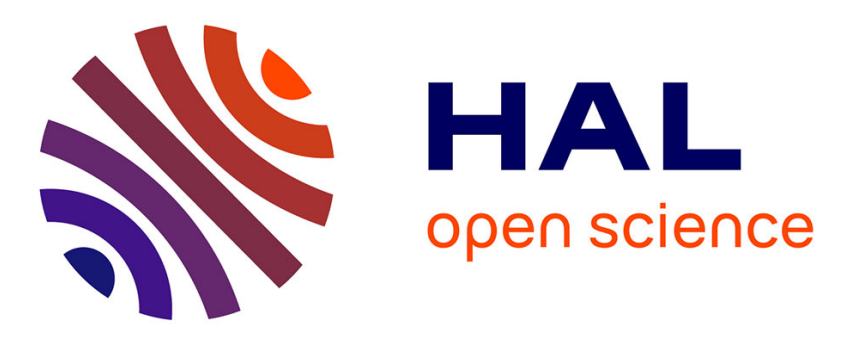

\title{
Average circulation, seasonal cycle, and mesoscale dynamics of the Peru Current System: A modeling approach
}

Pierrick Penven, Vincent Echevin, J. Pasapera, François Colas, Jorge Tam

\section{- To cite this version:}

Pierrick Penven, Vincent Echevin, J. Pasapera, François Colas, Jorge Tam. Average circulation, seasonal cycle, and mesoscale dynamics of the Peru Current System: A modeling approach. Journal of Geophysical Research, 2005, 110, pp.C10021. 10.1029/2005JC002945 hal-00124816

\section{HAL Id: hal-00124816 https://hal.science/hal-00124816}

Submitted on 18 Feb 2021

HAL is a multi-disciplinary open access archive for the deposit and dissemination of scientific research documents, whether they are published or not. The documents may come from teaching and research institutions in France or abroad, or from public or private research centers.
L'archive ouverte pluridisciplinaire HAL, est destinée au dépôt et à la diffusion de documents scientifiques de niveau recherche, publiés ou non, émanant des établissements d'enseignement et de recherche français ou étrangers, des laboratoires publics ou privés. 


\title{
Average circulation, seasonal cycle, and mesoscale dynamics of the Peru Current System: A modeling approach
}

\author{
P. Penven ${ }^{1}$ and V. Echevin ${ }^{2}$ \\ Institut de Recherche pour le Développement, Paris, France \\ J. Pasapera, F. Colas, and J. Tam \\ Instituto del Mar del Perú, Callao - Lima, Perú \\ Received 5 March 2005; revised 18 May 2005; accepted 11 July 2005; published 20 October 2005.
}

[1] The Humboldt Current System is the most productive of the eastern boundary currents. In the northern part, the Peru Current System (PCS) is located between $5^{\circ} \mathrm{S}$ and $20^{\circ} \mathrm{S}$. Along the Peruvian coast, an equatorward wind forces a strong coastal upwelling. A high resolution model is designed to investigate the mean circulation, the seasonal cycle, and the mesoscale dynamics for the PCS. The model is able to reproduce the equatorward Peru Coastal Current (PCC), the Peru Chile Under-Current (PCUC) which follows the shelf break towards the pole, and the Peru-Chile Counter-Current (PCCC) which flows directly towards the south and veers to the west around $15^{\circ} \mathrm{S}$. While the upper part of the PCUC is close to the surface and might even outcrop as a counter current, the bottom part follows $\frac{f}{H}$ isolines. The PCCC appears to be directly forced by the cyclonic wind stress curl. The model is able to produce the upwelling front, the cold water tongue which extends toward the equator and the equatorial front as described in the literature. Model seasonal changes in SST and SSH are compared to measurements. For the central PCS, model EKE is $10 \%$ to $30 \%$ lower than the observations. The model eddy diameters follow a strong equatorward increase. The injection length scales, derived from the energy spectra, strongly correlate to the Rossby radius of deformation, confirming the predominant role of baroclinic instability. At $3^{\circ} \mathrm{S}$, the model solution appears to switch from a turbulent oceanic regime to an equatorial regime dominated by zonal currents.

Citation: Penven, P., V. Echevin, J. Pasapera, F. Colas, and J. Tam (2005), Average circulation, seasonal cycle, and mesoscale dynamics of the Peru Current System: A modeling approach, J. Geophys. Res., 110, C10021, doi:10.1029/2005JC002945.

\section{Introduction}

[2] The Humboldt Current System is the most productive of the eastern boundary current systems. Its fisheries represent approximately $18-20 \%$ of the total worldwide marine fish catch (source: HLME web page). In the northern part, the Peru Current System (PCS) is located approximately between $5^{\circ} \mathrm{S}$ and $20^{\circ} \mathrm{S}$. Along the Peruvian coast, the Andes mountain range forces the south-east trade winds to blow northward [Strub et al., 1998; Gunther, 1936]. Although modulated by a strong sea breeze [Brink et al., 1983; Gunther, 1936], the wind is almost constantly favorable to upwelling, presenting an alongshore maximum in austral winter [Strub et al., 1998]. Hence, the PCS supports a permanent upwelling, responsible for extremely high levels of biological productivity all year [Chavez, 1995]. It differ-

\footnotetext{
${ }^{1}$ Also at Oceanography Department, University of Cape Town, Rondebosch, South Africa.

${ }^{2}$ Also at Laboratoire d'Oceanographie Dynamique et Climatologie (LODYC), Université Pierre et Marie Curie, Paris, France.

Copyright 2005 by the American Geophysical Union. 0148-0227/05/2005JC002945
}

entiates itself from the other upwelling systems by the lack of narrow fronts and strong jets [Hill et al., 1998]. More remarkably, this is the only eastern boundary upwelling system in proximity and direct connection to the equatorial Ocean [Lukas, 1986]. As a consequence, it is subjected to a dramatic interannual ENSO variability.

[3] The known large scale circulation is summarized in Figure 1. The surface layer is dominated by the equatorward flow of the Peru Current. This slow broad current originates from the split of the eastward west wind drift at around $43^{\circ} \mathrm{S}$. It has been observed at around $500-1000 \mathrm{~km}$ from the coast (see Figure 2 in Strub et al. [1998]), but there is no strict evidence of its precise location. Offshore, the Peru Oceanic Current (POC) extends from the surface to a depth of $700 \mathrm{~m}$, it follows the coast at a distance of $1000-1500 \mathrm{~km}$, and veers eastward around $15^{\circ} \mathrm{S}-20^{\circ} \mathrm{S}$ [Wyrtki, 1967].

[4] Holding to the coast, the surface equatorward Peru Coastal Current (PCC), also known as the Humboldt Current, is associated with the coastal upwelling of cold and salty water. It feeds the South Equatorial Current (SEC), forming the equatorial cold tongue visible in the north-west of Cabo Blanco $\left(4^{\circ} \mathrm{S}\right)$. The seasonal cycle of the PCC is not 


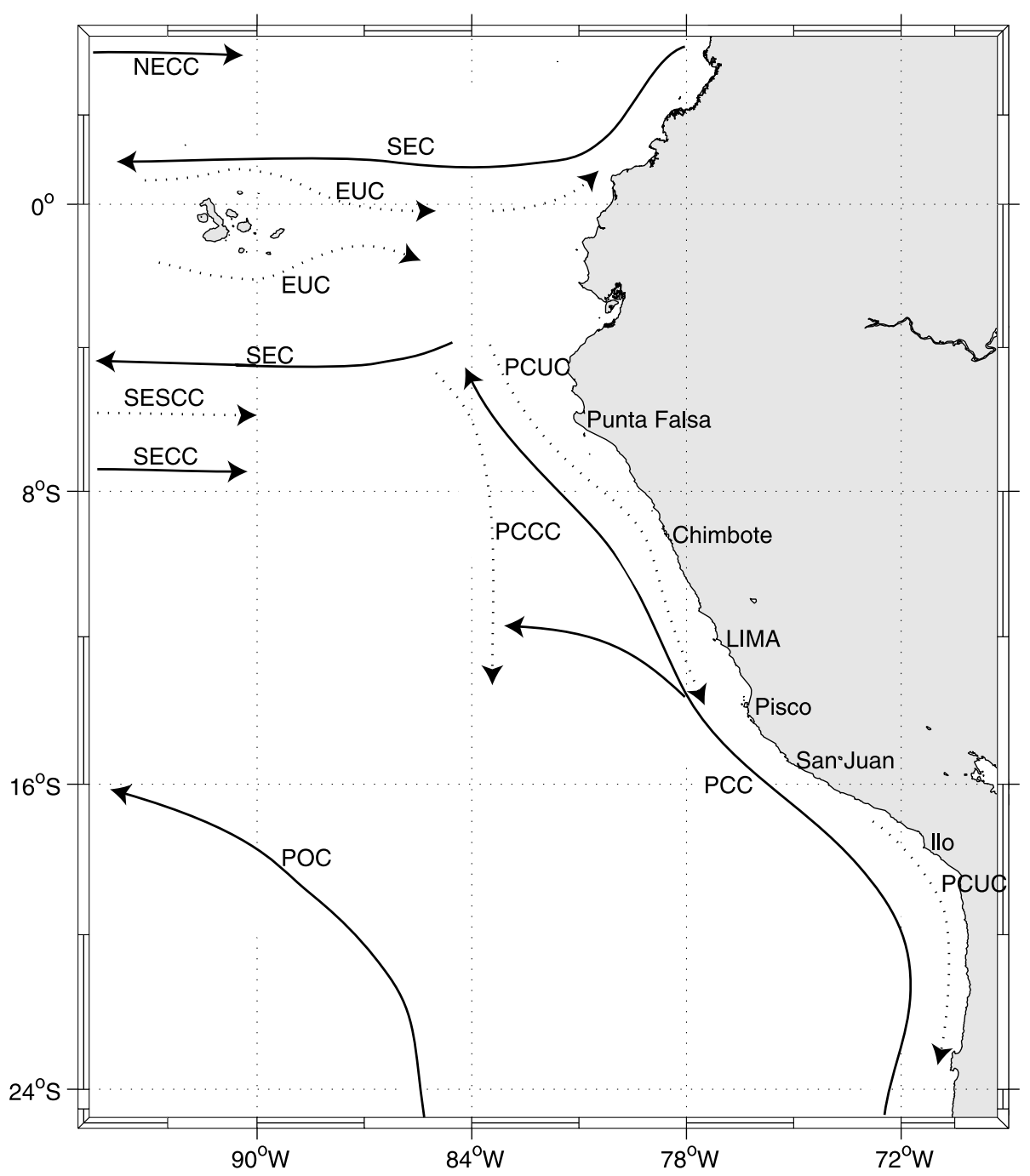

Figure 1. Oceanic circulation scheme, adapted from Gunther [1936], Wyrtki [1963, 1967], Tsuchiya [1985], Lukas [1986], Huyer et al. [1991], and Strub et al. [1998].

well known, although scarce measurements in the north indicate a maximum velocity in winter [Cucalon, 1987; Fiedler, 1994].

[5] Below a shallow upper layer $(\sim 20 \mathrm{~m})$ of equatorward current, poleward flow dominates the subsurface and the shelf [Brink et al., 1983]. The Peru Chile Under-Current (PCUC) flows poleward over the slope. It has a maximum core velocity near the slope of $15 \mathrm{~cm} . \mathrm{s}^{-1}$ at a depth of about 100-150 m [Huyer, 1980]. It dominates in the first $180 \mathrm{~km}$ from the coast [Fonseca, 1989], and extends to 600-700 m deep [Wyrtki, 1963]. The PCUC originates from the Equatorial Undercurrent (EUC) which splits at the Galapagos Islands. One branch continues as an undercurrent along the equator and turns south to form the PCUC, while the other branch flows southeastward to reach the coast at around $5^{\circ} \mathrm{S}$ [Lukas, 1986; Tsuchiya, 1985]. It transports salty waters, rich in nutrients and extremely low in oxygen [Gunther, 1936; Fonseca, 1989]. At $5^{\circ} \mathrm{S}$, the core of the PCUC has been directly observed at a depth of about $50-100 \mathrm{~m}$ whereas at $10^{\circ} \mathrm{S}$ it is located around $150-200 \mathrm{~m}$ with velocities of about $10 \mathrm{~cm} . \mathrm{s}^{-1}$ [Huyer et al., 1991]. The depth of the salinity maximum, a signature of the PCUC, also increases towards the south [Gunther, 1936]. The PCUC is recognized as a major source of upwelled water [Wyrtki, 1963; Brink et al., 1983]. It represents the largest transport in summer [Fonseca, 1989], but, off Chile, the variability of the coastal undercurrent has been shown to be dominated by intraseasonal and interannual signals [Shaffer et al., 1997].

[6] Offshore of the PCC and the PCUC, a tongue of warm water signifies the surface of the Peru Chile CounterCurrent (PCCC). The PCCC flows poleward at a few hundred kilometers from the coast [Strub et al., 1998]. Its origin is presumed to be the southern branch which results from the splitting of the EUC at the Galapagos Islands [Lukas, 1986; Hill et al., 1998]. Although there has been few direct measurements of this current, it has been detected by satellite altimeter data from approximately $8^{\circ} \mathrm{S}$ to $35^{\circ} \mathrm{S}$ at a distance of $100-300 \mathrm{~km}$ from the shore and shows a maximum in austral spring and a minimum in fall [Strub et al., 1995]. As explained by Strub et al. [1998], since the temporal mean was removed, these latter observations do not give any information on the mean circulation. For this reason, we should be suspicious of the description of the 


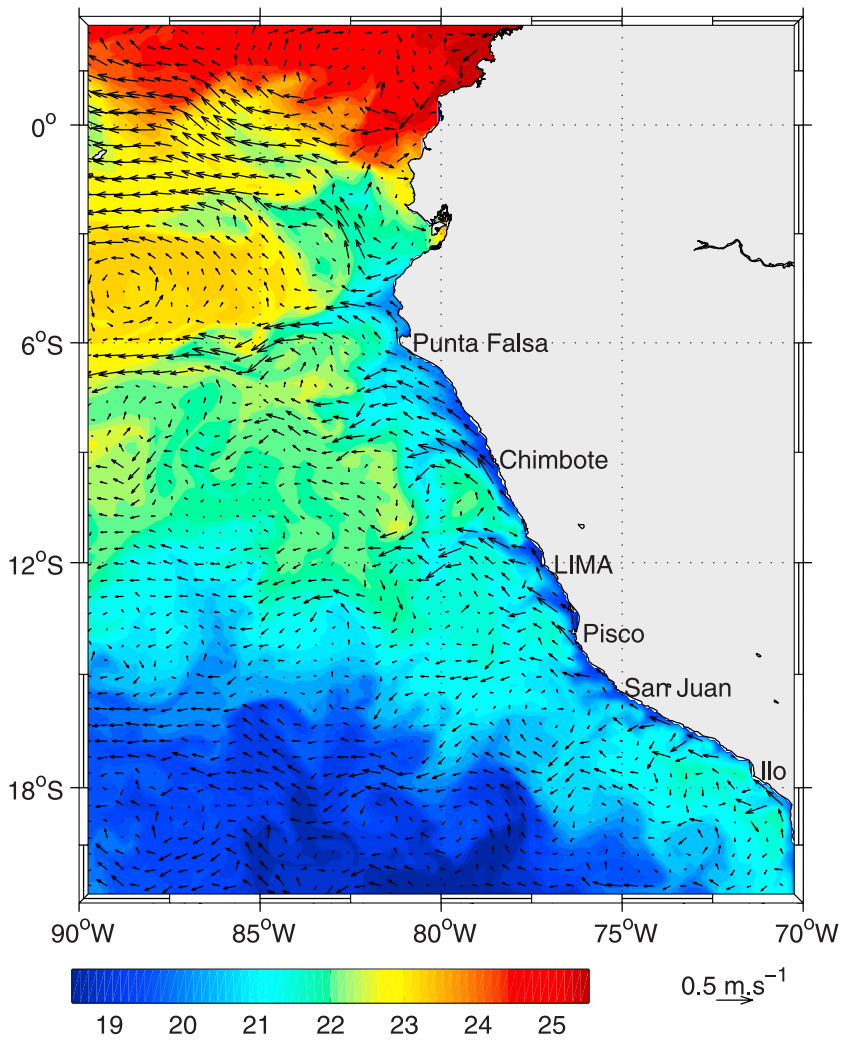

Figure 2. An example of modeled surface currents (1 vector every 4 grid points) and sea surface temperature $\left[{ }^{\circ} \mathrm{C}\right]$ for the 25 December of model year 10 .

PCCC given by Figure 10.2 in Strub et al. [1998]. For the time being, we would rather keep in mind the classic image of a PCCC flowing approximately due south, along about $80^{\circ} \mathrm{W}-84^{\circ} \mathrm{W}$, as depicted by Figures $17,18,19$, and 20 in Wyrtki [1963]. This representation also agrees with the observation of the core of the PCCC $200 \mathrm{~km}$ from the shore at $10^{\circ} \mathrm{S}$ [Huyer et al., 1991]. Its core appears to be shallower than the PCUC, with maximum velocities of $10 \mathrm{~cm} . \mathrm{s}^{-1}$ at $50 \mathrm{~m}$ [Huyer et al., 1991]. The dynamics responsible for the presence of this current and its connections to equatorial currents still remain unclear.

[7] At interannual scales, ENSO is the major contributor to variability: dramatically deepening the thermocline and strengthening the poleward currents, but with actually little reduction of equatorward winds [Strub et al., 1998; Hill et al., 1998]. On the other hand, on periods of 5 to 20 days, the principal source of variations appears to be mostly related to coastal trapped waves of equatorial origin [Hill et al., 1998; Brink et al., 1983]. Dominant variability in the PCUC has been measured in the 50-day band [Huyer et al., 1991]. Although in most upwelling systems one of the largest source of variability is associated to the instability of equatorward baroclinic jets [Hill et al., 1998; Marchesiello et al., 2003], very little is known on the turbulent processes in the PCS. Inshore counter currents have been seen to produce small scale cyclonic eddies [Gunther, 1936] and upwelling filaments are known to be shallow $(<50 \mathrm{~m})$, short $(25-50 \mathrm{~km})$ and transient (a few days) [Strub et al., 1998; Hill et al., 1998].
[8] While the PCS has been recently described in a review paper based on observations [Strub et al., 1998], there has been very few attempts to model the circulation [Preller and O'Brien, 1980]. In the presented work, in order to understand the dynamical processes at stake, a model is designed to reproduce the major features of the surface and sub-surface circulation for the PCS. As a first step, we chose to focus on the mean and seasonal circulation features, and to disregard the strong intraseasonal variability related to coastal trapped waves [Brink, 1982] or high and low frequency wind variability. In the following sections, we describe the circulation model main characteristics (section 2), the annual mean state (section 3), the seasonal cycle (section 4) and some characteristics of the mesoscale dynamics (section 5). In the last section, a summary concludes this work.

\section{Model Characteristics}

\subsection{ROMS Ocean Model}

[9] In this paper, the model employed is the Regional Oceanic Modeling System (ROMS). The reader is referred to Shchepetkin and McWilliams [2003] and to Shchepetkin and McWilliams [2005] for a more complete description of the model.

[10] ROMS solves the Primitive Equations in an Earthcentered rotating environment, based on the Boussinesq approximation and hydrostatic vertical momentum balance. ROMS is discretized in coastline- and terrain-following curvilinear coordinates.

[11] ROMS is a split-explicit, free-surface oceanic model, where short time steps are used to advance the surface elevation and barotropic momentum equations and where a much larger time step is used for temperature, salinity, and baroclinic momentum. ROMS employs a special 2-way time-averaging procedure for the barotropic mode which satisfies the $3 \mathrm{D}$ continuity equation. The specially designed predictor-corrector time step algorithm used in ROMS allows a substantial increase in the permissible time-step size.

[12] The third-order, upstream-biased advection scheme implemented in ROMS allows the generation of steep gradients, enhancing the effective resolution of the solution for a given grid size [Shchepetkin and McWilliams, 1998]. Explicit lateral viscosity is null everywhere in the model domain, except in sponge layers near the open boundaries where it increases smoothly on a few grid points.

[13] A nonlocal, K-profile planetary (KPP) boundary layer scheme [Large et al., 1994] parameterizes the subgrid-scale vertical mixing processes.

\section{2. "Peru Current System" Configuration}

[14] On Figure 1, one can note the complexity of the circulation in the PCS. In contrast to the other upwelling systems, the PCS is closely connected to the eastern limit of the equatorial currents [Lukas, 1986]. Hence, a model of the Peruvian upwelling should explicitly resolve the eastern equatorial dynamics. To encompass the whole domain including the equatorial currents and the Peruvian currents, we have chosen to design a rectangular grid going from $20^{\circ} \mathrm{S}$ to $3^{\circ} \mathrm{N}$ in latitude and from $90^{\circ} \mathrm{W}$ to $70^{\circ} \mathrm{W}$ in longitude (Figure 2). The model grid, forcing, initial and 
boundary conditions were built using the ROMSTOOLS package developed in the Institut de Recherche pour le Développement (IRD) [Penven, 2003].

[15] For the California Current System, Marchesiello et al. [2003] have proved that a resolution of at least 5 kilometers is necessary to resolve, with a high degree of accuracy, the mesoscale features. In our context, due to computer limitation, we were constrained to refine the model to a resolution of $1 / 9^{\circ}$ (i.e. $\sim 10 \mathrm{~km}$ ). One can note, that while the first-baroclinic Rossby radius of deformation ranges from $20 \mathrm{~km}$ to $30 \mathrm{~km}$ along the West Coast of the United States, it ranges from $50 \mathrm{~km}$ to more than $150 \mathrm{~km}$ along the Peruvian coastline [Chelton et al., 1998]. Consequently, although the grid is almost 2 times coarser than the one used for the California Current System, it still resolves, with a greater accuracy, the fastest growing length scales for baroclinic instability. We should thus expect that this experiment can produce a reasonable representation of the mesoscale dynamics in the PCS. The grid is isotropic and does not produce any asymmetry in the horizontal dissipation of turbulence. The horizontal grid contains $192 \times 240$ points.

[16] The bottom topography is derived from a 2' resolution database [Smith and Sandwell, 1997]. Although a new pressure gradient scheme associated to a specific equation of state limits errors in the computation of the pressure gradient [Shchepetkin and McWilliams, 2003], the bathymetry has been filtered in order to keep a "slope parameter" $r=\frac{\nabla h}{h}<0.2$ [Beckmann and Haidvogel, 1993]. To preserve a sufficient resolution in the upper ocean, the model possess 32 vertical levels. The vertical s-coordinate is also stretched $\left(\theta_{s}=6, \theta_{b}=0, h_{c}=10 \mathrm{~m}\right.$ [see Haidvogel and Beckmann, 1999]) in order to obtain a vertical resolution ranging from a minimum of $30 \mathrm{~cm}$ to a maximum of $6.25 \mathrm{~m}$ for the surface layer and from $31 \mathrm{~cm}$ to $1086 \mathrm{~m}$ for the bottom.

[17] In the present work, we desire to uniquely address the mean circulation and seasonal cycle in the PCS, leaving aside the interannual variability. For this reason, all the model external forcings are derived from climatologies. At the surface, the model heat fluxes and fresh water fluxes are extracted from the COADS ocean surface monthly climatology at $1 / 2^{\circ}$ resolution [Da Silva et al., 1994]. The thermal feedback of the model ocean surface temperature to the surface heat flux is represented as a correction with respect to the COADS sea surface temperature as described by Marchesiello et al. [2003]. The same type of correction is used for surface salinity flux since direct measurements of evaporation and precipitation are sparse. For the wind stress, a monthly mean climatology is computed from QuickSCAT satellite scatterometer data [Liu et al., 1998]. QuickSCAT data are gridded at a resolution of $1 / 2^{\circ}$ and were available, at this time, from October 1999 until March 2003. At the three lateral boundaries facing the open ocean, an active, implicit, upstream-biased radiation condition connects the model solution to the surroundings [Marchesiello et al., 2001]. In the case of inflow conditions, the solution at the boundary is nudged toward cyclic seasonal, time-averaged outputs of the OCCAM global ocean model at $1 / 4^{\circ}$ resolution [Saunders et al., 1999]. Thus, interannual signals such as El-Niños are explicitly excluded.
[18] For temperature and salinity, the January values of the OCCAM climatology was employed for the initial conditions. To perform the calculations, we have benefited from the Instituto del Mar del Perú in a form of a 4-processors Compaq Alpha workstation. ROMS was run in parallel on these 4 processors. On this platform, the model required 34 hours to calculate each year of simulation.

\subsection{Model Spin-Up}

[19] The model solution, starting from rest, quickly adjusts to the initial stratification and the model reaches a statistical equilibrium after a spin-up of about 2 years. Figure 2 presents a snapshot of the modeled surface currents and sea surface temperature for the 25 December of model year 10. One can notice the cold upwelled water along the shore, the upwelling filaments extending from the upwelling front, the equatorward flow along the shore, the offshore Ekman transport, and the strong SEC. This image is representative of the known dynamics in this region. The cold tongue extending northwestward from Punta Falsa to the equator is also a typical pattern observed for this time of year.

[20] A 10-year simulation is conducted to attain a nearly repeating annual cycle. Figure 3 depicts the time variations of surface-averaged kinetic energy (Figure 3a), volumeaveraged kinetic energy (Figure 3b), surface-averaged temperature (Figure 3c), volume-averaged temperature (Figure 3d), surface-averaged salinity (Figure 3e), and volume-averaged salinity (Figure 3f). For each of these variables, after a spin-up of 2 years, the model exhibits no significant temporal drift. This is especially true for the volume-averaged kinetic energy (Figure 3b): after a rapid adjustment of the currents to the initial conditions, the level of kinetic energy increases following the growing eddy activity during the 2 first years of simulation. After which, it stays particularly stable. A slight adjustment of surface-averaged salinity (Figure 3e) and volume-averaged salinity (Figure $3 \mathrm{f}$ ) is also noticeable in the 2 first years of simulation. The model solution is analyzed from year 3 to year 10 .

[21] At the beginning of each year, a sharp peak occurs in the time variations of surface-averaged kinetic energy (Figure 3a). These variations in surface kinetic energy are only present in the $3^{\circ} \mathrm{S}-3^{\circ} \mathrm{N}$ equatorial region (figure not shown), i.e. in the SEC. Since this signal is not seen in the local equatorial winds employed to force the model, this should be related to large scale seasonal variations in the equatorial Ocean. During these events, the SEC reaches a speed of about $80 \mathrm{~cm} . \mathrm{s}^{-1}$ during approximately one month, whereas it flows at about $50 \mathrm{~cm} \cdot \mathrm{s}^{-1}$ the rest of the year. This very regular phenomenon appears in conjunction to intrusions of tropical, relatively fresh waters from the northeastern part of the domain by the Annual El-Niño Current as described by Strub et al. [1998].

\section{Annual Mean}

\subsection{Annual Mean Surface Circulation}

[22] To represent the simulated annual mean circulation, instead of showing vector fields, it appeared clearer to derive a streamfunction from the model outputs. The Helmholtz theorem allows us to decompose any horizontal 

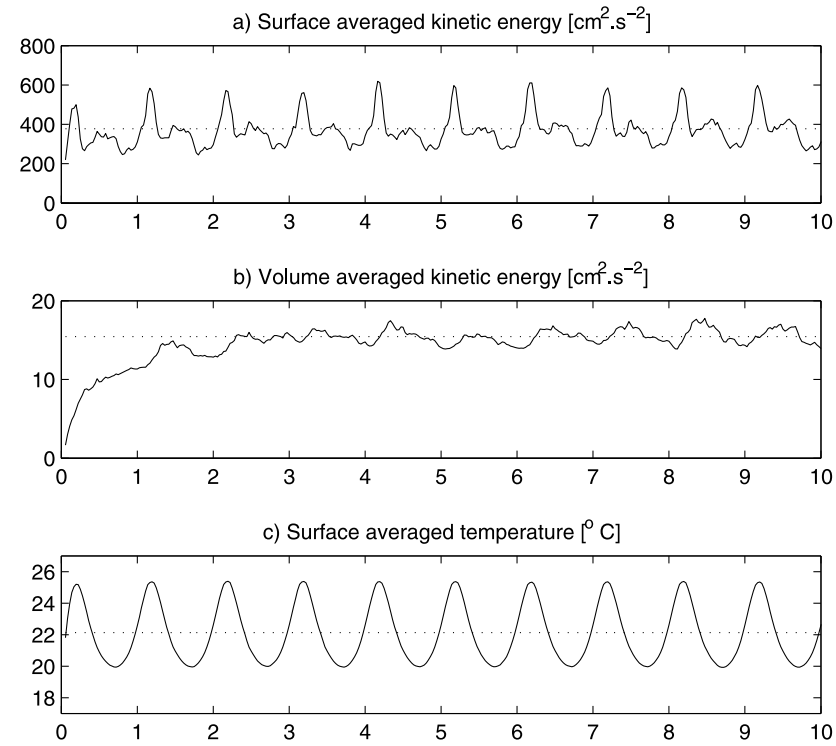

d) Volume averaged temperature $[\mathrm{C}]$
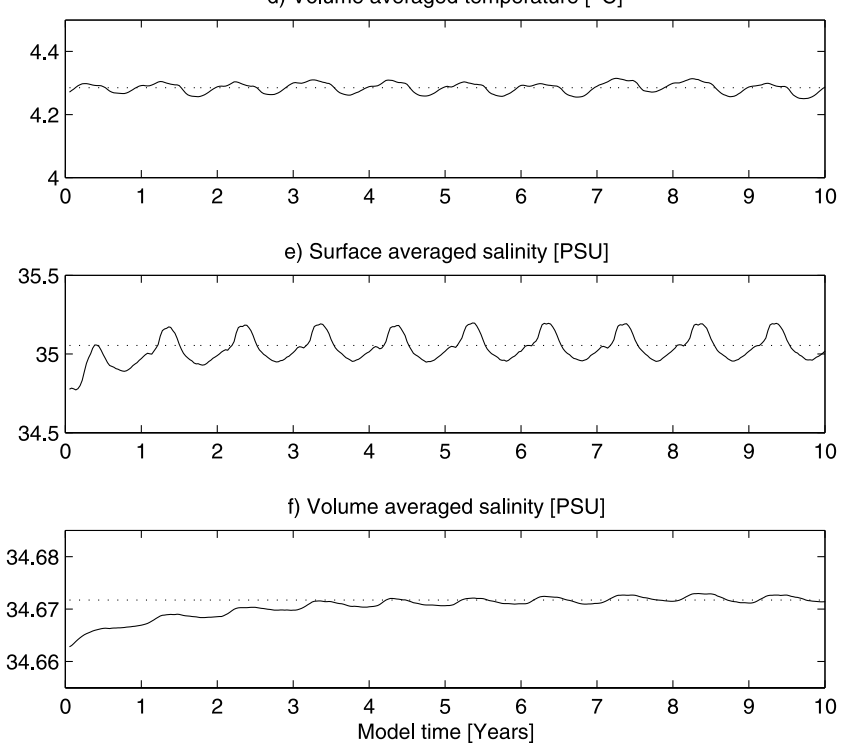

Figure 3. Time evolution of different model variables: (a) surface-averaged kinetic energy $\left[\mathrm{cm}^{2} \cdot \mathrm{s}^{-2}\right]$, (b) volumeaveraged kinetic energy $\left[\mathrm{cm}^{2} . \mathrm{s}^{-2}\right]$, (c) surface-averaged temperature $\left[{ }^{\circ} \mathrm{C}\right]$, (d) volume-averaged temperature $\left[{ }^{\circ} \mathrm{C}\right]$, (e) surface-averaged salinity [PSU], and (f) volumeaveraged salinity [PSU].

flow $\vec{u}$ into two parts: an irrotational component and a nondivergent component

$$
\vec{u}=\vec{k} \wedge \nabla \Psi-\nabla \Phi
$$

where $\vec{k}$ is a vertical unit vector, $\Psi$ is a streamfunction representative of the nondivergent component of the flow, and $\Phi$ is a potential. Taking the curl of the previous equation, we can derive $\Psi$ from the Laplace equation:

$$
\nabla^{2} \Psi=(\nabla \wedge \vec{u}) \cdot \vec{k}
$$

This equation is solved by applying an integral constraint for mass conservation on currents for the lateral boundary conditions. The correction which is applied to ensure the integral constraint is at least one order of magnitude smaller than the mean velocities. Although it is solely representative of the nondivergent component of the flow, we felt that a horizontal streamfunction was more explicit than vector diagrams for the description of the average circulation. In average, the nondivergent component accounts for at least $70 \%$ of the total flow. The divergent component presents a maximum along the coast in the northern part of the model domain. It vanishes where the flow is close to geostrophy.

[23] The streamfunction, representative of the nondivergent component of the surface annual mean currents, is portrayed on Figure 4. The principal surface currents described by Wyrtki [1963], Lukas [1986], and Strub et al. [1998] are present in this depiction. In this simulation, the South Equatorial Current (SEC) extends from about $2^{\circ} \mathrm{N}$ to $2^{\circ} \mathrm{S}$. It flows westward with velocities in the $25 \mathrm{~cm} \cdot \mathrm{s}^{-1}$ $40 \mathrm{~cm} \cdot \mathrm{s}^{-1}$ band. An important part is fed by a recirculation of the North Equatorial Counter Current (NECC) that stems from the northern model boundary as described by Lukas [1986].

[24] At the western border, around $4^{\circ} \mathrm{S}$, a branch of the South Equatorial Counter Current (SECC) enters the model domain with velocities of about $10 \mathrm{~cm} \cdot \mathrm{s}^{-1}$ to $15 \mathrm{~cm} \cdot \mathrm{s}^{-1}$. It veers northward to recirculate into the SEC. South of $6^{\circ} \mathrm{S}$, the PCS is dominated at large scale by a surface equatorward wind drift with velocities ranging from 5 to $10 \mathrm{~cm} \cdot \mathrm{s}^{-1}$. At the shore, a squeezing of the isolines reveals the Peru Coastal Current, flowing northward close to the

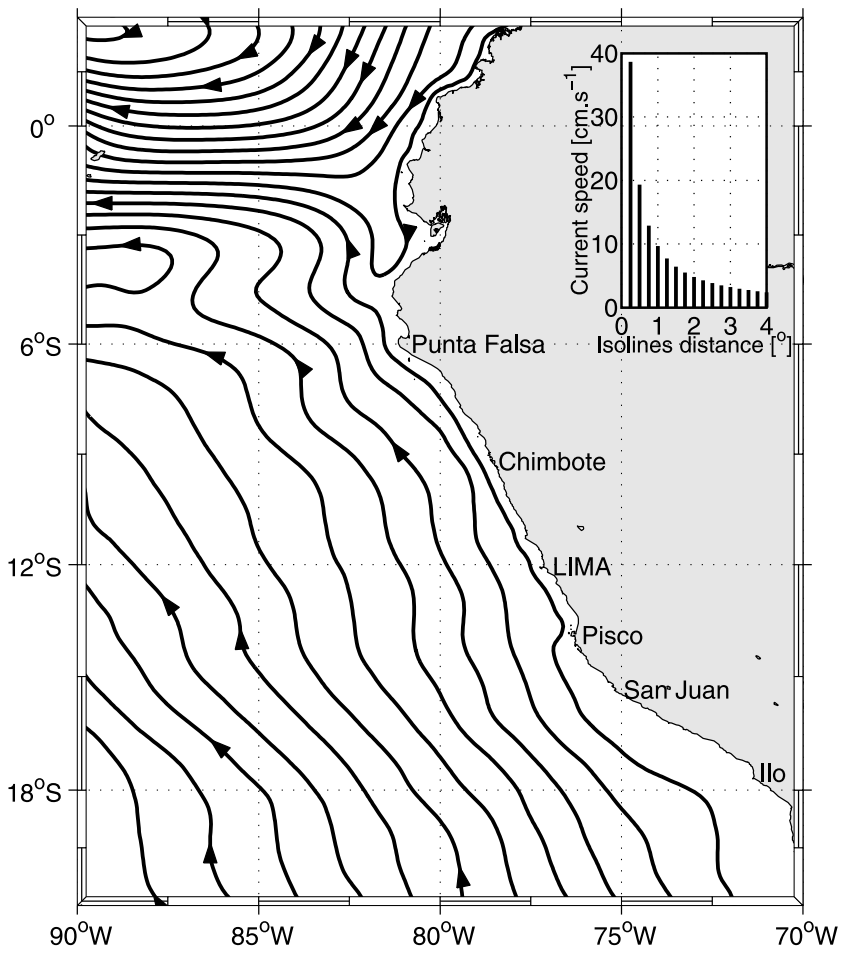

Figure 4. Streamfunction derived from the annual mean surface velocities. The interval between the isocontours is $10^{-4} \mathrm{~m}^{2} . \mathrm{s}^{-1}$. A diagram presenting the distances between the isolines and the corresponding currents speeds is inserted in the upper-right corner. 


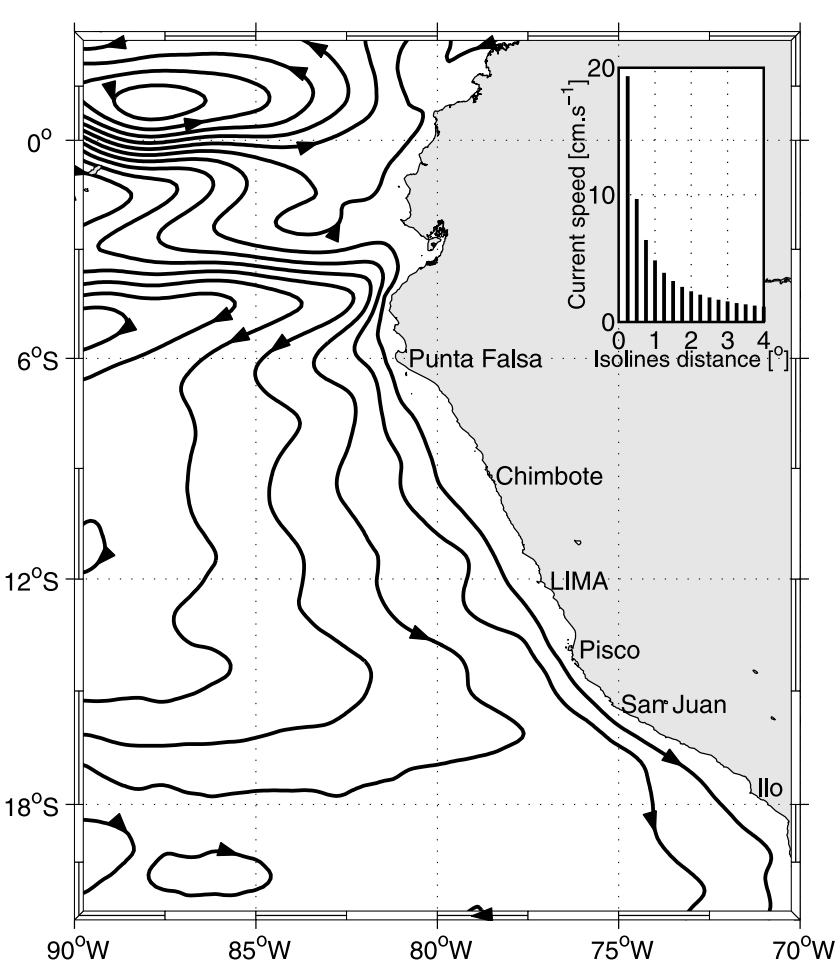

Figure 5. Streamfunction derived from the annual mean velocities at $50 \mathrm{~m}$ depth. The interval between the isocontours is $0.5 \times 10^{-4} \mathrm{~m}^{2} . \mathrm{s}^{-1}$.

Peruvian coastline with velocities ranging from $10 \mathrm{~cm} . \mathrm{s}^{-1}$ to $25 \mathrm{~cm} . \mathrm{s}^{-1}$. It is analyzed in more detail in section 3.3.

[25] Although the scarceness of observations prevents a true quantitative comparison, this depiction reflects the capacity of the model to reproduce the known surface circulation.

\subsection{Annual Mean Subsurface $(50 \mathrm{~m})$ Circulation}

[26] Direct measurements have demonstrated that below a thin surface Ekman layer, poleward flows dominate the subsurface and the shelf [Brink et al., 1983]. Figure 5 presents a streamfunction calculated from the modeled annual mean velocities at $50 \mathrm{~m}$ depth. In comparison to Figure 4, the circulation is totally reversed, in agreement to what is expected.

[27] In Figure 5, at $50 \mathrm{~m}$ depth, the PCUC is already noticeable at the shore with speeds of about $5 \mathrm{~cm} . \mathrm{s}^{-1}$ to $15 \mathrm{~cm} . \mathrm{s}^{-1}$. Part of this flow is fed by the EUC (current speed: $20 \mathrm{~cm} . \mathrm{s}^{-1}$ to $30 \mathrm{~cm} . \mathrm{s}^{-1}$ ) and the SECC that enters the model domain at about $4^{\circ} \mathrm{S}$ with speeds of about $10 \mathrm{~cm} . \mathrm{s}^{-1}$ to $20 \mathrm{~cm} \cdot \mathrm{s}^{-1}$. The SECC also clearly feeds the PCCC that flows southward at about $5 \mathrm{~cm} . \mathrm{s}^{-1}$ from a latitude of $6^{\circ} \mathrm{S}$. The PCCC is veering westward to leave the model domain between $15^{\circ} \mathrm{S}$ and $18^{\circ} \mathrm{S}$. Whereas the modeled subsurface circulation follows precisely the schematic of circulation presented in Figure 1, to our knowledge, the latter pattern has not been yet observed. This offshore veering could be a plausible explanation for the termination of the PCCC. This pattern is confirmed in section 3.4.

[28] Figure 5 can be compared to the subsurface circulation portrayed by Figures 18 and 19 in Wyrtki [1963] and by Figure 7 in Tsuchiya [1985]. The recirculation of the SECC in our model is very similar to that shown by Wyrtki [1963]. In particular, our simulation shows the connection between the SECC, the PCCC and the PCUC, all in agreement with the diagram proposed by Tsuchiya [1985]. On the other hand, we do not get an significant subsurface signal for the offshore POC as observed by Wyrtki [1963]. This discrepancy might be caused by the limited extent of the model domain.

[29] Although they have used only seasonal anomalies derived from satellite altimetry, Strub et al. [1995] suggested that the PCCC remains relatively close to the shore $(100-300 \mathrm{~km})$ flowing from $7^{\circ} \mathrm{S}$ to about $35^{\circ} \mathrm{S}-40^{\circ} \mathrm{S}$. Figure 5 presents a much broader $\mathrm{PCCC}$, situated from $300 \mathrm{~km}$ to $600 \mathrm{~km}$ offshore. The simulated PCCC and PCUC spatial variability are analysed in more detail in section 3.4.

\subsection{Mean Vertical Structure of the Peru Upwelling System}

[30] The central portion of the Peru Upwelling System, between $7^{\circ} \mathrm{S}$ and $13^{\circ} \mathrm{S}$ (i.e from Pisco to south of Punta Falsa), follows a relatively rectilinear coastline. In this area, the bottom topography presents very few alongshore variations and the upwelling system should encounter quasihomogeneous alongshore conditions. Therefore, an alongshore average from $7^{\circ} \mathrm{S}$ to $13^{\circ} \mathrm{S}$ should be representative of the cross-shore upwelling structure of the central PCS.

[31] Vertical cross sections of annual mean temperature, averaged from $13^{\circ} \mathrm{S}$ to $7^{\circ} \mathrm{S}$, are displayed on Figure 6. Three data sets are presented: the World Ocean Atlas 2001 (WOA) [Conkright et al., 2002] (Figure 6a), OCCAM (Figure 6b), and our simulation (Figure $6 \mathrm{c}$ ). Although WOA data are at a relatively low resolution, they are employed here as reference for the baroclinic structure. OCCAM data are also presented as they are used in our simulation for initial and boundary conditions.

[32] The most striking feature for the PCS is the very sharp thermocline (Figure 6a). It consists of a marked gradient in temperature (more than $10^{\circ} \mathrm{C} / 100 \mathrm{~m}$ ) at around $50 \mathrm{~m}$ depth. Above $100 \mathrm{~m}$, one can note the isotherms shoaling towards the coast, a signature of coastal upwelling. The signal is stronger as the surface is approached. Between $100 \mathrm{~m}$ and $400 \mathrm{~m}$ depth, the isotherms show a slight downward tilt towards the shore. The temperature cross sections published for $10^{\circ} \mathrm{S}$ (Figures 11 and $12 \mathrm{~b}$ in Huyer et al. [1991]) and for $12^{\circ} \mathrm{S}$ (Figure 32 in Gunther [1936]) (although the latter is slightly cooler at the surface) are in agreement with this depiction. At $15^{\circ} \mathrm{S}$, Gunther [1936, Figure 33], Brink et al. [1983, Figure 8], and Huyer [1980, Figure 5] observed much colder waters at the shore (i.e. $14^{\circ} \mathrm{C}-15^{\circ} \mathrm{C}$ ). This difference is probably caused by the large horizontal correlation scales employed in WOA.

[33] Although OCCAM compares relatively well to WOA below $500 \mathrm{~m}$, it definitely lacks the subsurface thermocline (Figure 6b). The 100 first meters appears strongly mixed, and a relatively weak temperature gradient $\left(\sim 2.5^{\circ} \mathrm{C} / 100 \mathrm{~m}\right)$ is present between $100 \mathrm{~m}$ and $400 \mathrm{~m}$. This discrepancy might be related to spurious diapycnal mixing and/or to large scale drifts arising during OCCAM simulations. This issue has been addressed by Lee et al. [2002] in the case of bottom water for the Southern Ocean. Diagnosed 


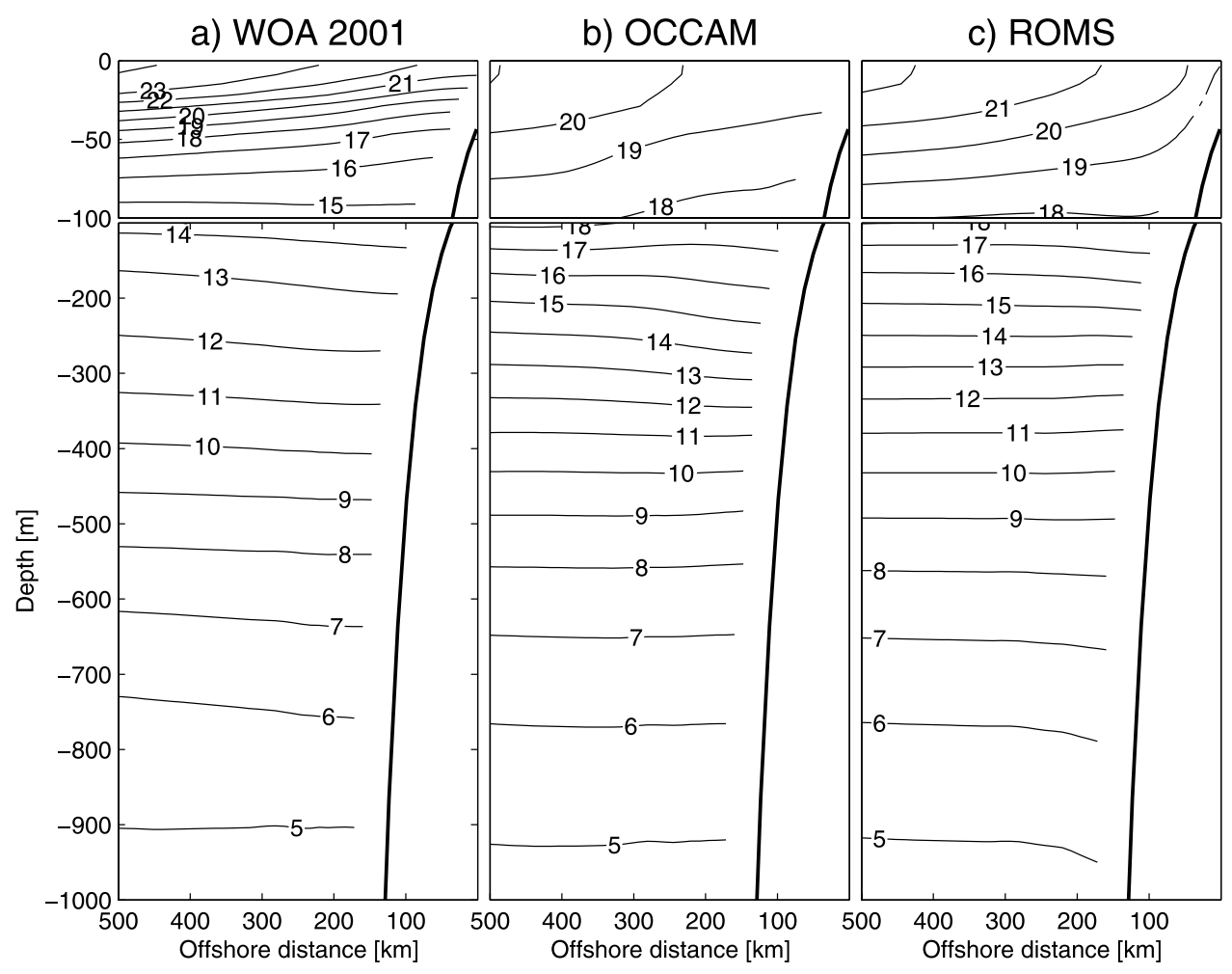

Figure 6. Annual mean temperature $\left[{ }^{\circ} \mathrm{C}\right]$ for the Central Peruvian Upwelling region, averaged from to $13^{\circ} \mathrm{S}$ to $7^{\circ} \mathrm{S}$. (a) WOA 2001, (b) OCCAM model, and (c) ROMS model.

numerical diapycnic diffusivity was found of the same order of magnitude (i.e. $1-10 \mathrm{~cm}^{2} \cdot \mathrm{s}^{-1}$ ) as the explicit horizontal diffusion. The resulting thermocline shape in the PCS is more reminiscent of an El-Niño year than a normal year (Figure 10.8 in Strub et al. [1998]). This difference can affect the upwelling structure since more colder water is present in the vicinity of the shelf for WOA than for OCCAM. Variations in baroclinic structure might also affect baroclinic instability processes [Marchesiello et al., 2004] and consequently, turbulent transport.

[34] Because ROMS employs OCCAM data for its initial and boundary conditions, it results with more or less the same large scale vertical hydrologic structure (Figure 6c). This emphasizes that the use of an OGCM in order to force coastal or regional simulations implies that large scale biases from the OGCM will be propagated in the local model, independently of the local model. Nevertheless, due to the local surface heat forcing, and due to the boundary layer parameterization [Large et al., 1994], ROMS surface dynamics actually builds up a subsurface thermocline. As a result, close to surface, while OCCAM is more than $3^{\circ} \mathrm{C}$ colder than WOA, ROMS reduces the differences to only $1.5^{\circ} \mathrm{C}$. Between $100 \mathrm{~m}$ and $400 \mathrm{~m}$, ROMS keeps the OCCAM large scale warm bias.

[35] In the case of salinity, WOA presents a weak halocline $(\sim 0.1 \mathrm{PSU} / 100 \mathrm{~m})$ between $250 \mathrm{~m}$ and $550 \mathrm{~m}$ and shows very few variations above and below (Figure 7a). For this variable, both OCCAM and ROMS coincide to the observations (Figures $7 \mathrm{~b}$ and $7 \mathrm{c}$ ). Neither of them deviates more than 0.12 PSU from WOA. Disregarding a saltier lens (35.5 PSU) lying at about $100 \mathrm{~km}$ offshore, OCCAM and ROMS are also both in agreement to what has been observed on board R.R.S. "William Scoresby" (Figure 44 in Gunther [1936]).

[36] Annual mean alongshore current for the central PCS are portrayed on Figure 8. For WOA, the geostrophy is derived chosing a reference level at $500 \mathrm{~m}$. The three data sets are showing the undercurrent (i.e. the PCUC) offshore of the coastal upwelling jet. It flows along the shelf edge, the core located between $50 \mathrm{~m}$ and $100 \mathrm{~m}$ with maximum speeds around $4 \mathrm{~cm} \cdot \mathrm{s}^{-1}$. This is slightly slower to what Huyer et al. [1991] has observed at $10^{\circ} \mathrm{S}\left(6 \mathrm{~cm} . \mathrm{s}^{-1}\right.$ at $100 \mathrm{~m}$ on the shelf) and to what Brink et al. [1983, Figure 8] has measured at $15^{\circ} \mathrm{S}\left(\sim 5 \mathrm{~cm} \cdot \mathrm{s}^{-1}\right)$. The upper part of this poleward flow is extremely close $(\sim 5 \mathrm{~m})$ to the Ocean surface, and might even outcrop as a poleward counter current, offshore of the PCC.

[37] The three data sets are in disagreement in their representation of the PCC (i.e. the Humboldt Current). This nearshore, equatorward current is about $200 \mathrm{~km}$ wide, with velocities up to $6 \mathrm{~cm} . \mathrm{s}^{-1}$ for WOA (Figure 8a), almost inexistent in the case of OCCAM (Figure 8b), and, in our simulation, it is limited to a band $100 \mathrm{~km}$ wide, is approximately $50 \mathrm{~m}$ deep, with maximum speeds of about 18 $\mathrm{cm} . \mathrm{s}^{-1}$ (Figure 8c). Although very few direct measurements have been made, these values can be compared to the estimate of a PCC $100 \mathrm{~km}$ wide, $50 \mathrm{~m}$ deep with maximum current speeds above $14 \mathrm{~cm} . \mathrm{s}^{-1}$ at $10^{\circ} \mathrm{S}$ (Figure 11 in Huyer et al. [1991]), or above $10 \mathrm{~cm} \cdot \mathrm{s}^{-1}$ at $15^{\circ} \mathrm{S}$ (Figure 8 in Brink et al. [1983]). This confirms the ability of the model to reproduce the coastal dynamics of the PCC.

[38] ROMS also generates a wind forced surface equatorward Ekman current, restricted to a shallow $(10 \mathrm{~m})$ boundary layer, with mean speeds of about $4 \mathrm{~cm} . \mathrm{s}^{-1}$. 
a) WOA 2001

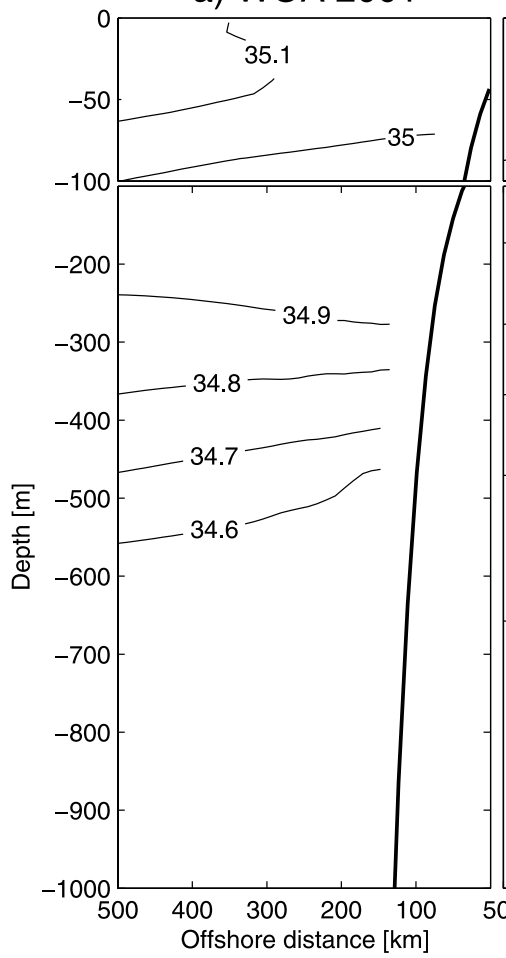

b) OCCAM

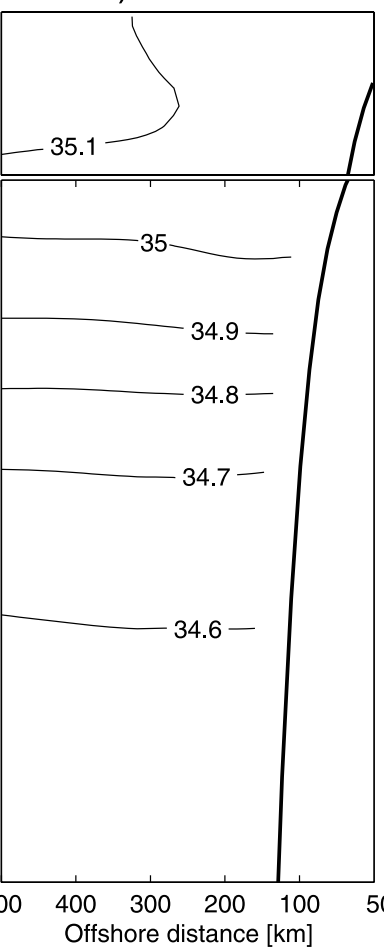

c) ROMS

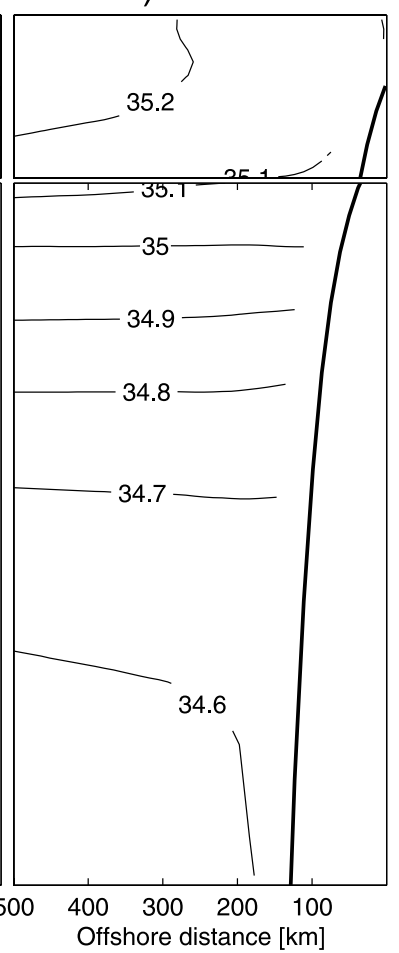

Figure 7. Annual mean salinity [PSU] for the Central Peruvian Upwelling region, averaged from to $13^{\circ} \mathrm{S}$ to $7^{\circ} \mathrm{S}$. (a) WOA 2001, (b) OCCAM model, and (c) ROMS model.

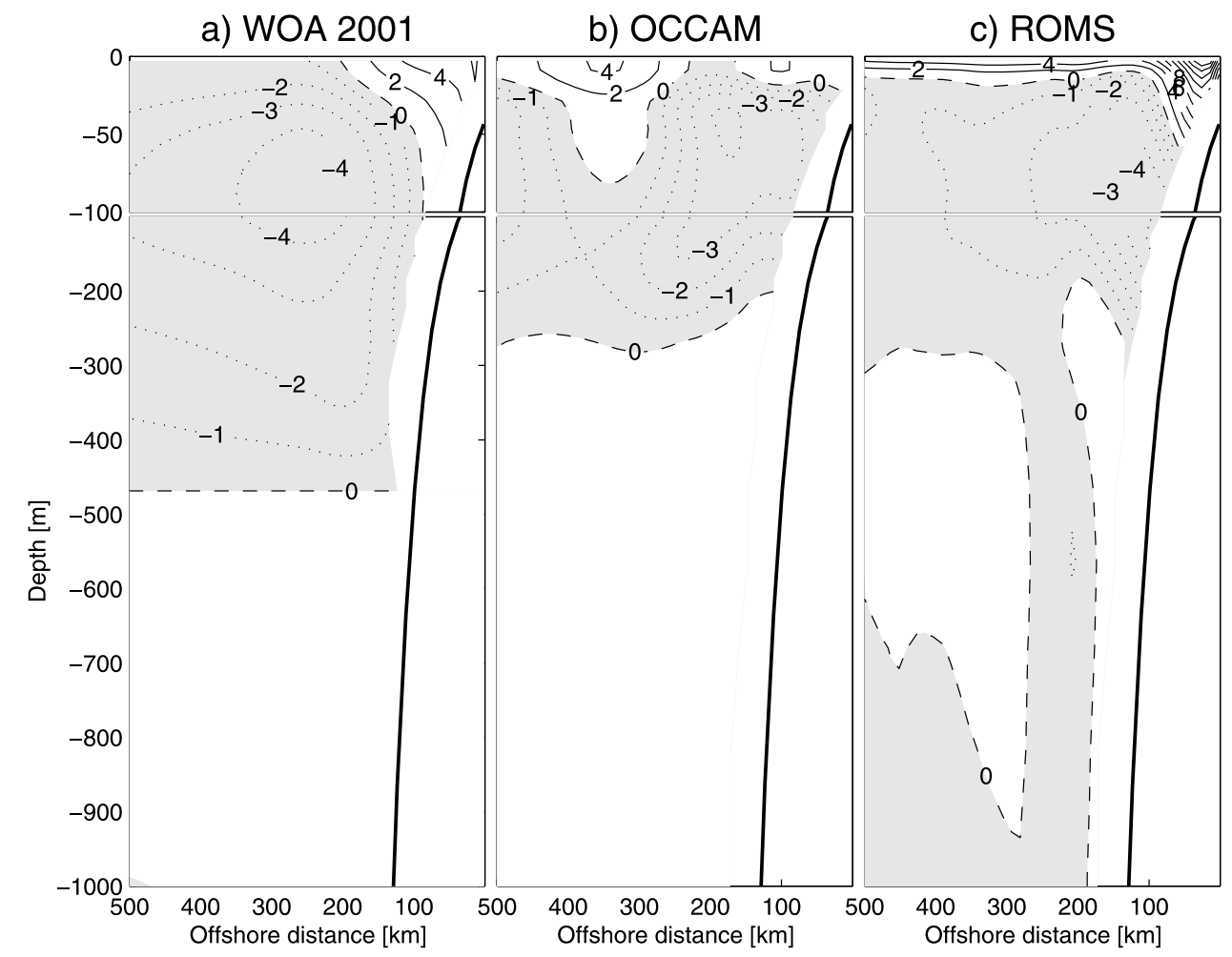

Figure 8. Annual mean alongshore currents $\left[\mathrm{cm} \cdot \mathrm{s}^{-1}\right]$ for the Central Peruvian Upwelling region, averaged from to $13^{\circ} \mathrm{S}$ to $7^{\circ} \mathrm{S}$. (a) Geostrophic currents derived from WOA 2001, (b) OCCAM model, and (c) ROMS model. 
Below, a subsurface secondary maximum for the poleward flow is noticeable at about $450 \mathrm{~km}$ from the shore and at $25 \mathrm{~m}$ depth (Figure 8c). This might be a signature of the PCCC. Below $300 \mathrm{~m}$, OCCAM presents almost no current (Figure 8b). In the case of ROMS, the flow is relatively sluggish, with a slow equatorward current $\left(\sim 1 \mathrm{~cm} . \mathrm{s}^{-1}\right)$ at the shore at a depth of about $300 \mathrm{~m}$, and a weak poleward movement below (Figure 8c).

\subsection{Poleward Under and Counter Currents}

[39] The PCUC and the PCCC are fundamental elements of the PCS. In this section, we analyze in greater detail the along shore variations of these currents. Figure 9 presents the vertical cross-sections of the annual mean alongshore currents off Punta Falsa $\left(6^{\circ} \mathrm{S}\right)$, Chimbote $\left(9.4^{\circ} \mathrm{S}\right)$, Callao $\left(12.1^{\circ} \mathrm{S}\right)$, Pisco $\left(14^{\circ} \mathrm{S}\right)$, San Juan $\left(15.7^{\circ} \mathrm{S}\right)$ and Arica $\left(18.6^{\circ} \mathrm{S}\right)$. For each latitude, the PCUC is close to the shore in a band of about $100 \mathrm{~km}$ in width, with top velocities that could attain $8 \mathrm{~cm} \cdot \mathrm{s}^{-1}$. Huyer et al. [1991, Figure 5] present two vertical profiles of subsurface currents for relatively long periods $(\sim 200$ days $)$ at $5^{\circ} \mathrm{S}$ and $10^{\circ} \mathrm{S}$. At $5^{\circ} \mathrm{S}$, they observed the core of the PCUC at about $100 \mathrm{~m}$, with maximum poleward velocities ranging from $10 \mathrm{~cm} \cdot \mathrm{s}^{-1}$ (during El Niño) to $4 \mathrm{~cm} \cdot \mathrm{s}^{-1}$ (after El Niño) and a bottom extension located between $250 \mathrm{~m}$ and $300 \mathrm{~m}$. Off Punta Falsa $\left(6^{\circ} \mathrm{S}\right)$, our model produces a PCUC with a core at $100 \mathrm{~m}$, a maximum current speed of $8 \mathrm{~cm} \cdot \mathrm{s}^{-1}$, and a lower limit at about $300 \mathrm{~m}$ (Figure 9a). For $10^{\circ} \mathrm{S}$, Huyer et al. [1991] have measured a PCUC with a core at about $150 \mathrm{~m}$, maximum velocities ranging from $2 \mathrm{~cm} . \mathrm{s}^{-1}$ (before and during El Niño) to $11 \mathrm{~cm} \cdot \mathrm{s}^{-1}$ (after El Niño), and a bottom extension ranging from about $250 \mathrm{~m}$ (before and during El Niño) to more than $400 \mathrm{~m}$ (after El Niño). Off Chimbote $\left(9.4^{\circ} \mathrm{S}\right)$, our model produces a PCUC with a core at $175 \mathrm{~m}$, maximum speeds of about 4 to $6 \mathrm{~cm} . \mathrm{s}^{-1}$, and a lower limit at around $300 \mathrm{~m}$ (Figure 9b). For the northern part of the PCS, our model is able to reproduce a PCUC at a correct location, with a correct vertical extension, and with currents situated within the range of the observations.

[40] As noted in the previous section, for each latitude, the PCUC is not located under the equatorward upwelling jet, but rather offshore. The upper part of the current is also situated very close to the surface and might even outcrop at about $100 \mathrm{~km}$ from the shore off Pisco, San Juan and Arica. This appears to be consistent with the results obtained with a linear model by McCreary and Chao [1985] who showed that the undercurrent may reach the surface in the case of cyclonic wind stress curl. In fact, the wind stress curl drives a mean poleward flow, in agreement with Sverdrup dynamics. This poleward current merges with the coastal undercurrent depending on its width, depth and strength. Off Pisco, there are two distinct cores of poleward flow, one corresponding to the coastal, upwelling-driven, undercurrent, and the other to the curldriven flow. For example, the patterns displayed on Figure $9 \mathrm{~d}$ present strong similarities with the results of McCreary and Chao [1985, Figure 9, left].

[41] To test the influence of the wind stress curl on the poleward flow, we have derived the Sverdrup relation using the annual mean wind stress employed to force our model. From Figure 8, we decided to take a fixed surface active layer depth of $200 \mathrm{~m}$. Following this assumption, the Sverdrup relation takes the form [Sverdrup, 1947]:

$$
H_{0} \beta \frac{\partial \Psi}{\partial x}=\nabla \wedge \frac{\vec{\tau}}{\rho_{0}}
$$

where $H_{0}$ is the depth of the active layer $(200 \mathrm{~m}), \beta$ is the rate of change of Coriolis parameter with latitude $(\sim 2.2 \times$ $\left.10^{-11} \mathrm{~s}^{-1} \cdot \mathrm{m}^{-1}\right), \psi\left[\mathrm{m}^{2} \cdot \mathrm{s}^{-1}\right]$ is the streamfunction, $\rho_{0}$ is the density of sea water $\left(\sim 1025 \mathrm{~kg} . \mathrm{m}^{-3}\right)$, and $\vec{\tau}\left[\mathrm{N} \cdot \mathrm{m}^{-2}\right]$ is the annual mean wind stress computed from QuickSCAT satellite scatterometer data [Liu et al., 1998]. Equation (3) is integrated westward from the eastern boundary using $\Psi=$ 0 for the coastal boundary condition. The resulting streamfunction is presented in Figure 10. A marked resemblance between Figure 5 and Figure 10 is apparent. The streamfunction which is derived from the Sverdrup relation is able to reproduce a SECC with speeds ranging from 6 to $10 \mathrm{~cm} \cdot \mathrm{s}^{-1}$, a PCUC with speeds ranging from 4 to $6 \mathrm{~cm} \cdot \mathrm{s}^{-1}$, and even a POC that leaves the domain around $18^{\circ} \mathrm{S}$ with speeds of about 2 to $6 \mathrm{~cm} \cdot \mathrm{s}^{-1}$. Although the choice of $H_{0}$ is somehow arbitrary, Figure 10 shows that at least half of the PCUC could be explained by the direct effect of a vigorous cyclonic wind stress curl, ubiquitous along the Peruvian coastline. This might be the reason why the PCUC outcrops at some places directly offshore of the PCC.

[42] Although, when deriving equation (3), we have neglected all motions below a surface layer of constant depth $H_{0}$, we can note on Figure 9 that the bottom part of the PCUC strongly interacts with the slope and it clearly deepens when it flows towards the south. If we consider the bottom limit of the PCUC as the maximum depth of the $2 \mathrm{~cm} . \mathrm{s}^{-1}$ isoline; the depth of the lower part of the current is $240 \mathrm{~m}$ off Punta Falsa, $280 \mathrm{~m}$ off Chimbote, $310 \mathrm{~m}$ off Callao, $470 \mathrm{~m}$ off Pisco, $550 \mathrm{~m}$ at San Juan, and $620 \mathrm{~m}$ off Arica (Figure 9). If we now regard this alongshore poleward flow as a barotropic subsurface layer isolated from the surface, neglecting bottom friction and the other non diabiatic processes, it should preserve its potential vorticity. In a first approximation, we can neglect the relative vorticity, which is in our simulation, at $50 \mathrm{~m}$ depth south of $5^{\circ} \mathrm{S}$, 1 order of magnitude lower than the Coriolis parameter. Hence, the potential vorticity takes the form:

$$
\frac{f}{H}=c s t .
$$

(where $\mathrm{f}$ is the Coriolis parameter and $\mathrm{H}$ is the thickness of the layer). Off Punta Falsa, for a homogenous layer $240 \mathrm{~m}$ thick, the potential vorticity attains $-8 \times 10^{-8} \mathrm{~s}^{-1} \cdot \mathrm{m}^{-1}$. Using this value, the bottom part of the current should be at about $340 \mathrm{~m}$ off Chimbote, $430 \mathrm{~m}$ off Callao, $490 \mathrm{~m}$ off Pisco, $560 \mathrm{~m}$ off San Juan, and $640 \mathrm{~m}$ off Arica. The stars in Figure 9 represent these depths. Thus, off the Peruvian coastline, the bottom part of PCUC appears to follow $\frac{f}{H}$ isolines, causing it to deepen as it flows away from the equator. Other theories can also predict the poleward deepening of the PCUC. McCreary [1981] used a continuously stratified, linear, flat bottom, wind forced ocean model to study the California undercurrent. The core of the undercurrent deepens poleward of the wind patch, 


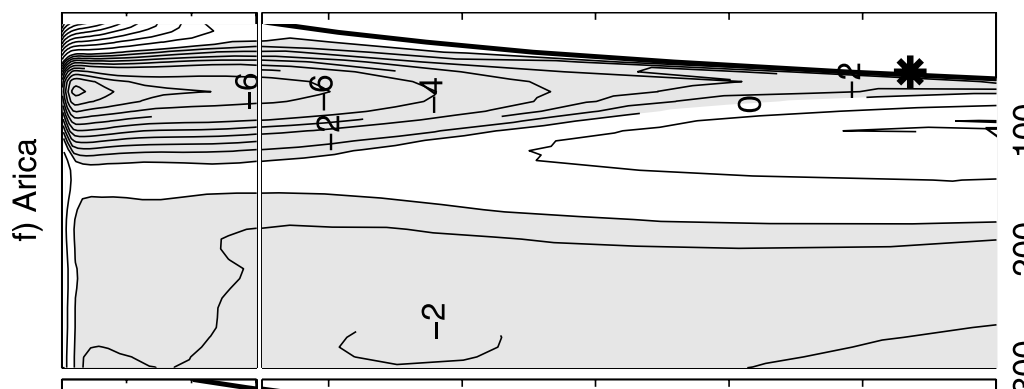

荘 용

ㅇํㅁ

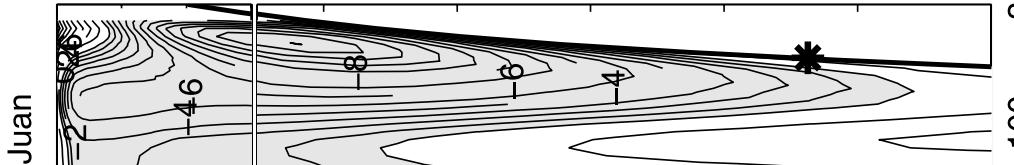

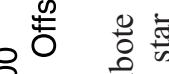

慁号

疍

$\circ \stackrel{0}{0}$.

की

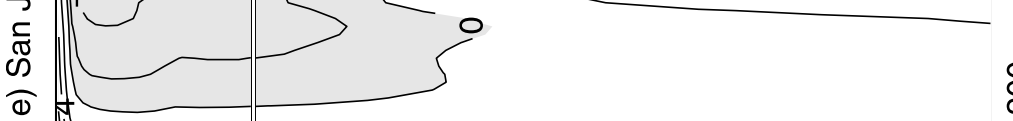

过

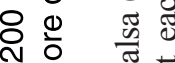

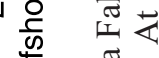

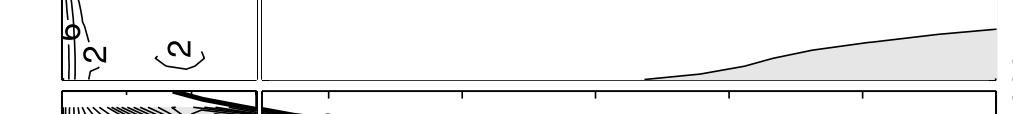

吅产会

छ
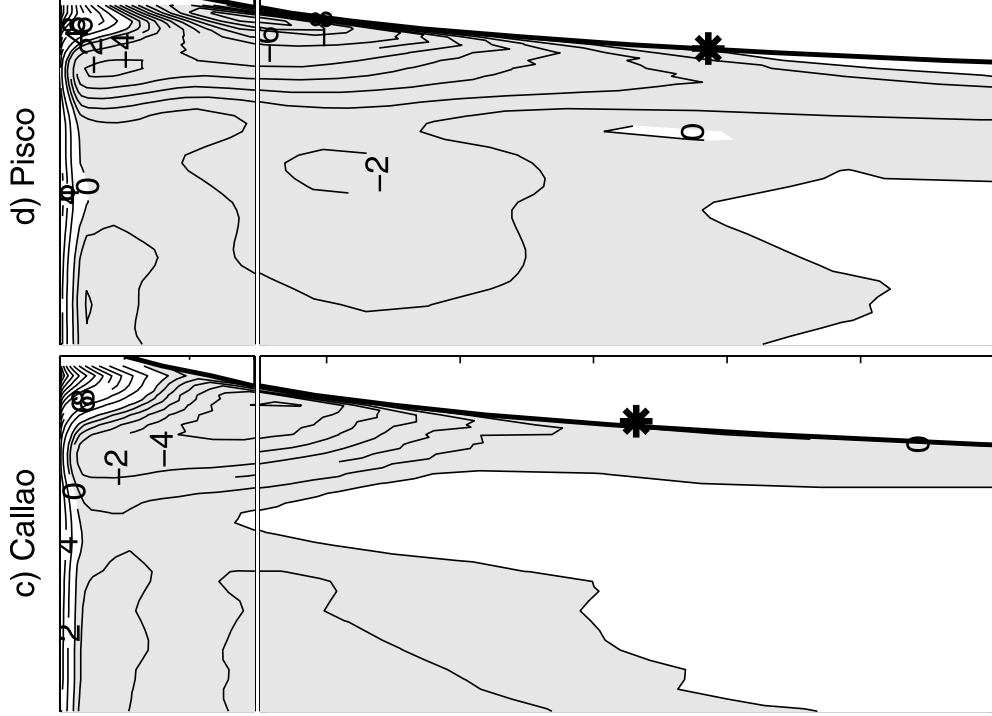

음

出.

要

○

항

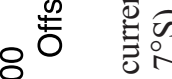

ㅌ

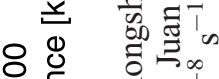

西 元

至

จ

ठํ.

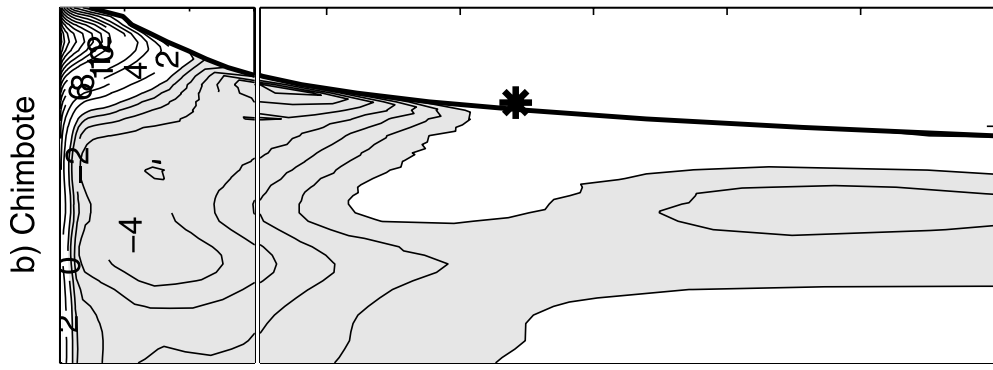

唡

垔

8 ․ㅡㅇ

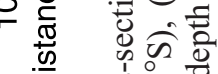

○

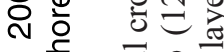

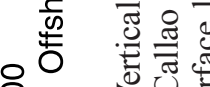

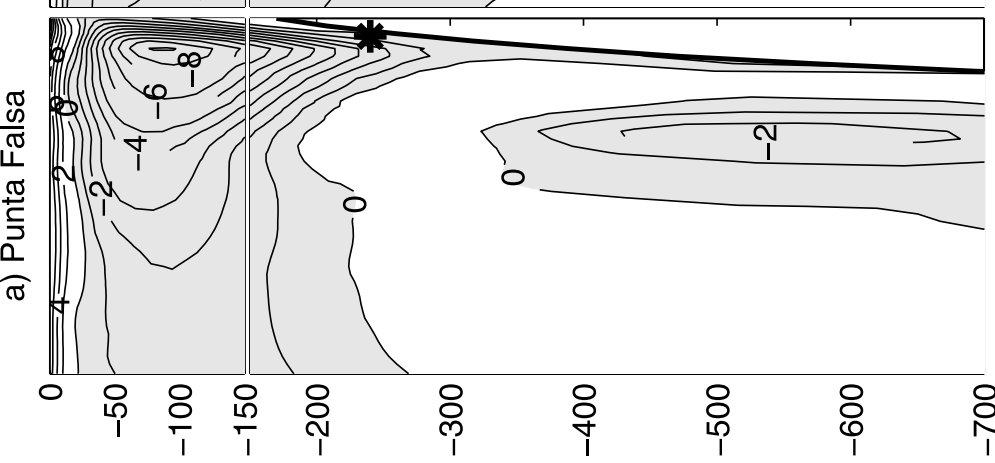

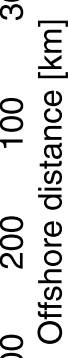

. (0)

$\circ-\pi$

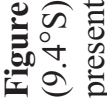

[w] पाdəC 


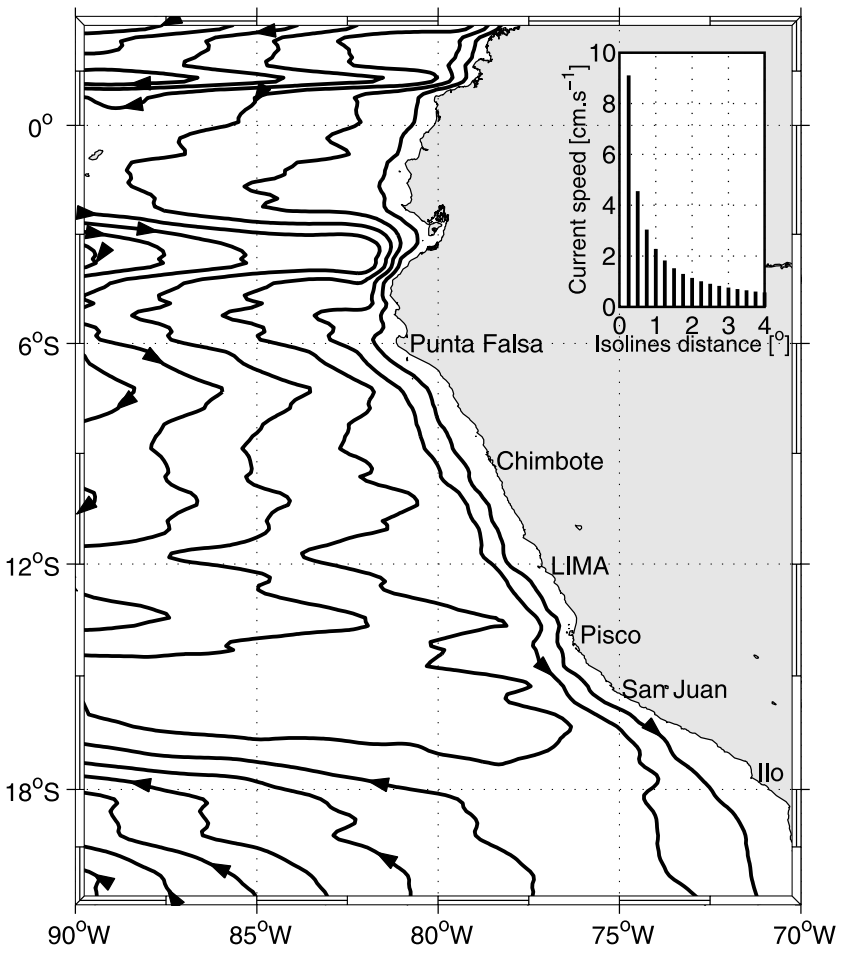

Figure 10. Streamfunction derived from the Sverdrup relation. The interval between the isocontours is $0.25 \times$ $10^{-4} \mathrm{~m}^{2} \cdot \mathrm{s}^{-1}$.

as the lower order vertical modes decay slower than the high order ones, and produce a deeper alongshore flow [Clarke, 1989]. Pizarro [1999] used a similar model to study the vertical and alongshore variability of the PCUC. He showed that the undercurrent core depth and intensity increased sligthly from $100 \mathrm{~m}$ at $15^{\circ} \mathrm{S}$ to $200 \mathrm{~m}$ at $20^{\circ} \mathrm{S}$ due to the significant alongshore wind decrease between these latitudes.

[43] A secondary maximum of poleward current is also noticeable at about $200 \mathrm{~km}$ offshore of Chimbote, $250 \mathrm{~km}$ offshore of Callao and almost $300 \mathrm{~km}$ offshore of Pisco (Figures 9b, 9c, and 9d). This is a very good candidate for the PCCC. This is in agreement with Figure 5 and with the geopotential topography map shown by Figure 18 in Wyrtki [1963]. Off Punta Falsa, the PCCC appears undicernible from the PCUC (Figure 9a). It starts to separate further in the south with a core at about $75 \mathrm{~m}$ depth, $200 \mathrm{~km}$ offshore of Chimbote (Figure 9b). Although the poleward flow is weaker in the model, the section off Chimbote is comparable to the findings of Huyer et al. [1991, Figure 11]: the PCUC at $200 \mathrm{~m}$ on the shelf edge, the PCCC located $200 \mathrm{~km}$ offshore at about $75 \mathrm{~m}$, and an equatorward movement at $300 \mathrm{~m}$, about $150 \mathrm{~km}$ from the shore (Figure 9b). Flowing south, the PCCC is located further offshore off Callao $(\sim 250 \mathrm{~km}$, Figure $9 \mathrm{c})$ and off Pisco ( $\sim 300 \mathrm{~km}$, Figure 9d). It gets also shallower: from $75 \mathrm{~m}$ off Chimbote, to $50 \mathrm{~m}$ off Callao, to $40 \mathrm{~m}$ off Pisco. The section off San Juan (Figure 9e) does not extend offshore enough in order to keep track of the PCCC. As explained in section 3.2, the path of the PCCC is clearly observable on Figure 5. It flows southward from about $6^{\circ} \mathrm{S}$, and veers westward to leave the domain between $15^{\circ} \mathrm{S}$ and $18^{\circ} \mathrm{S}$. This pattern is identical on Figure 10 . Hence, the PCCC appears to be a large-scale southward flow, directly forced by the wind stress curl, which is cyclonic in the PCS, north of $15^{\circ} \mathrm{S}$.

[44] Our model might help to clarify a point made by Strub et al. [1998]: although the PCCC was originally thought to flow straight south, Strub et al. [1995] observed a band of poleward current which followed the coast at a distance of 100-300 km offshore. The currents that Strub et al. [1995] refer to as the PCCC on their Figures 1 and 2 might correspond to the outcropping of the PCUC shown in Figure 9. Our model makes a clear distinction between the outcroping of the PCUC, which creates a surface counter current offshore of the PCC, and the PCCC that actually flows south and veers west around $15^{\circ} \mathrm{S}$.

\section{Seasonal Cycle}

\subsection{Sea Surface Temperature}

[45] Locally forced, or remotely forced by equatorial propagating signals, the Peru Upwelling exhibits an important seasonal cycle in sea surface temperature. Figure 11 presents the seasonal variations of sea surface temperature for the $0.5^{\circ}$ resolution COADS climatology from 1854 to 1993 [Da Silva et al., 1994] (first column), the $9.28 \mathrm{~km}$ resolution Pathfinder climatology from 1985 to 1997 [Casey and Cornillon, 1999] (second column), and the ROMS model (third column). As COADS sea surface temperature is used as a correction for the model heat fluxes, comparisons between the model forcing (COADS), the model solution, and a more precise data set (Pathfinder) can help to obtain an evaluation of the model skills. Because they are computed over different periods, using different types of data, and using distinct averaging procedures; COADS and Pathfinder appear quite dissimilar. Since it uses a very large radius of influence for its objective analysis, COADS climatology is known to be very smooth.

[46] In general, sea surface temperature in ROMS is around $0.5^{\circ} \mathrm{C}$ colder than both COADS and Pathfinder. As seen in section 3.3, the large-scale bias present in the OCCAM thermocline induces cooler surface temperatures in ROMS, although ROMS local surface fluxes are able to reduce this error.

[47] In summer (Figures 11a, 11b, and 11c), the three products present a strong coastal upwelling signature. They are very similar at a large scale, showing warm water at the equator and colder water in the south. A patch of warm water is also present around $90^{\circ} \mathrm{W}$ and $6^{\circ} \mathrm{S}$. ROMS and Pathfinder are similar in their representation of the upwelling front and the cold water tongue extending toward the equator. This proves the quality of the surface currents simulated by ROMS, which improve the sea surface temperature patterns, even in comparison to what is used as model forcing. A few biases are noticeable in ROMS: the sea surface temperature close to the shore is slightly too cold, and the upwelling along the coast appears too continuous. This issue has been addressed by Penven et al. [2001] in their model of the Benguela Upwelling System. They related this cold bias to the wind being slightly too strong at the shore. Indeed, QuikSCAT observations are not valid on a band of $50 \mathrm{~km}$ from the 
a) COADS summer

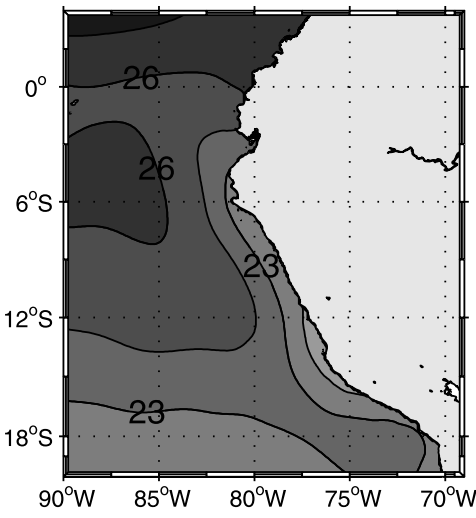

d) COADS fall

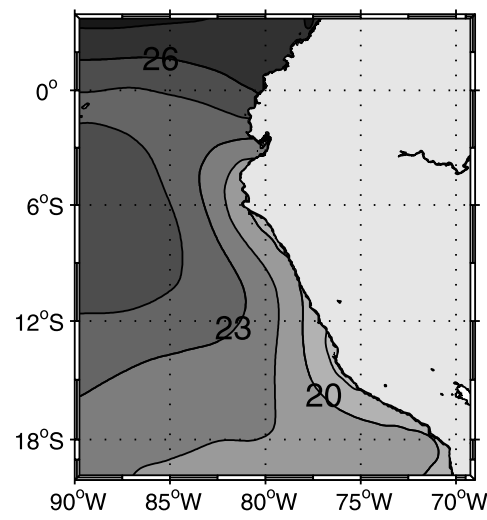

g) COADS winter
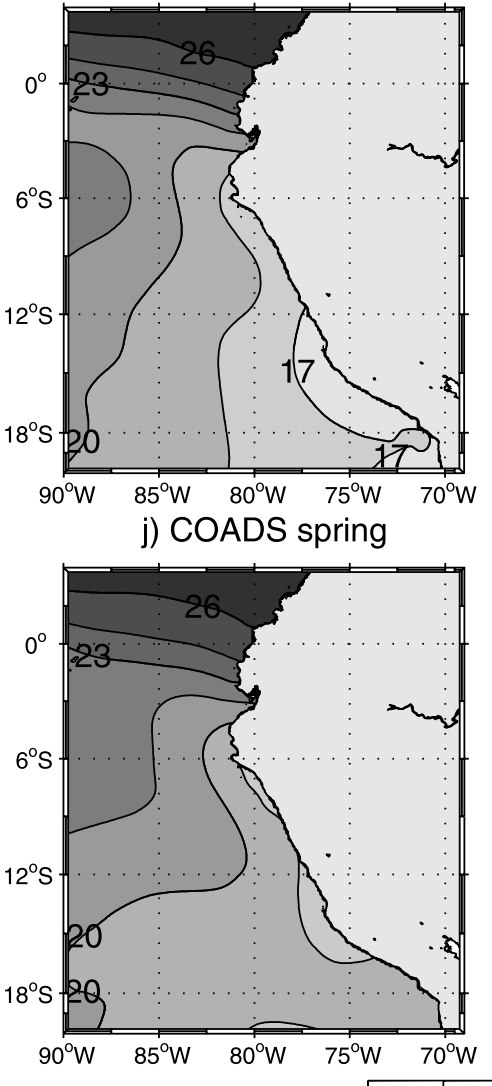

b) Pathfinder summer

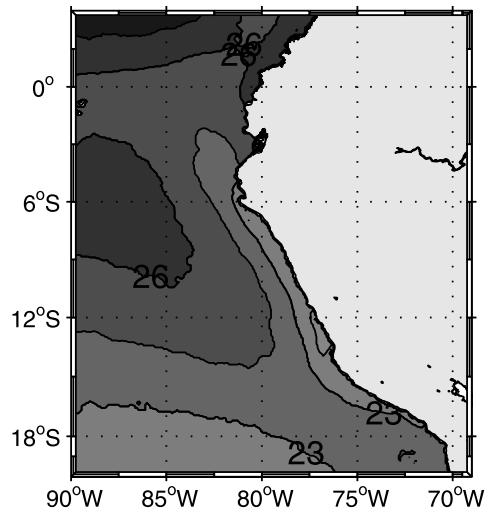

e) Pathfinder fall

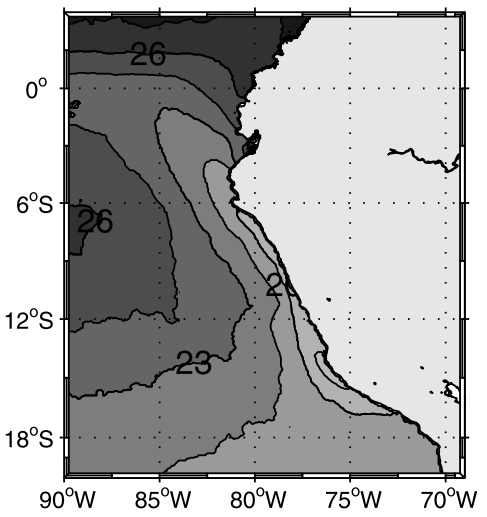

h) Pathfinder winter

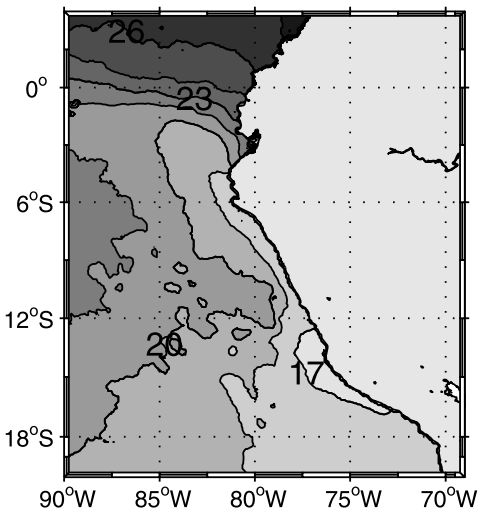

k) Pathfinder spring

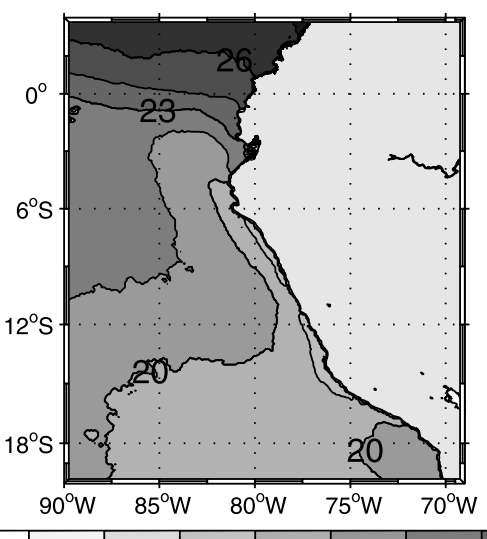

c) ROMS summer

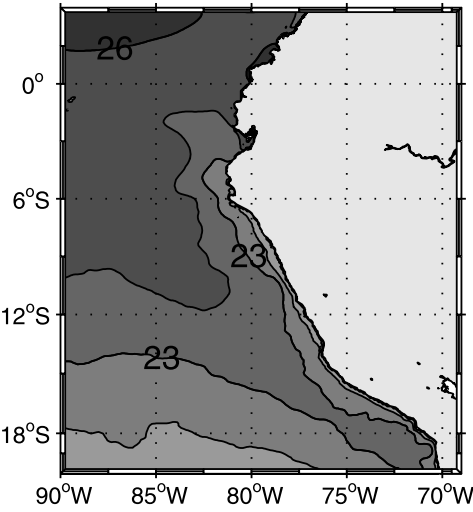

f) ROMS fall

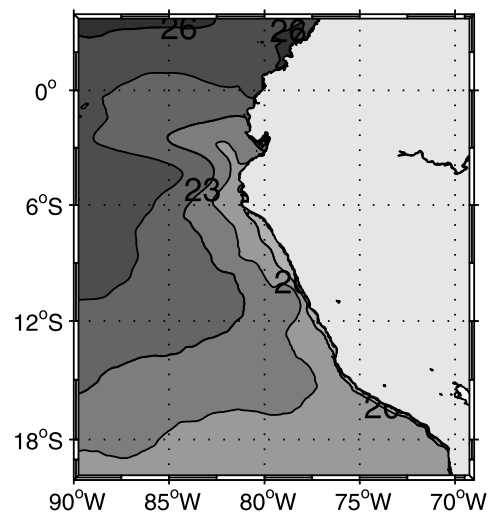

i) ROMS winter

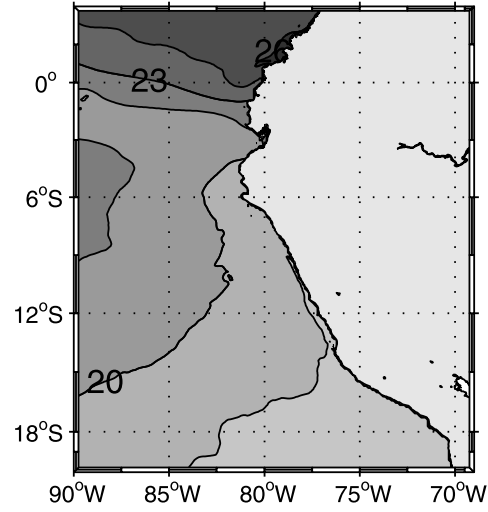

I) ROMS spring

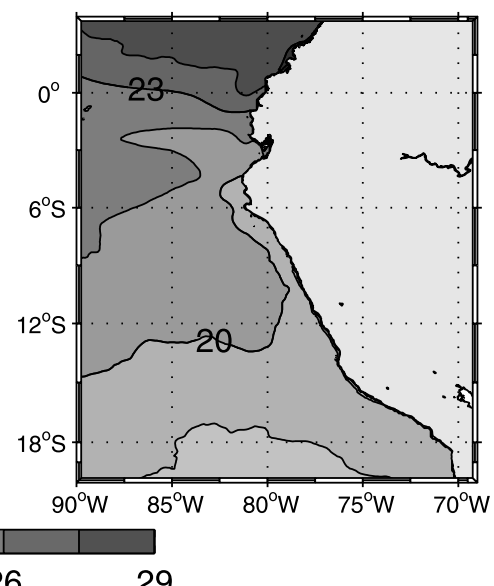

Figure 11 
coast. Nevertheless, coastal winds were extrapolated from offshore; short scale coastal variations, such as those observed in the California Current System [Kindle et al., 2002; Capet et al., 2004], are not present in the model wind forcing.

[48] Upwelling is still strong in fall (Figures 11d, 11e, and 11f). ROMS is able to generate a northward cold water tongue that mimics the cold tongue which is observable in Pathfinder data. Two main differences can be noted. Firstly, the orientation of the cold tongue in Pathfinder is very rectilinear, whereas, in ROMS it shows a significant westward tilt. This might be related to slight variations in the large-scale equatorial currents. Secondly, there is a coastal patch of colder water noticeable in Pathfinder around $15^{\circ} \mathrm{S}$, just offshore of Pisco. This is related to a persistent upwelling plume extending from the coast in the region of Pisco - San Juan $\left(14^{\circ} \mathrm{S}-16^{\circ} \mathrm{S}\right)$. A probable explanation of this phenomenon is the existence in this area of a local coastal wind, known as the "Paracas wind". During the JOINT II project, in March and April 1976 and in March to May 1977, Moody et al. [1981] performed several aircraft measurements of the sea surface temperature and the wind along the Peruvian coastline around $15^{\circ} \mathrm{S}$. They observed a distinct upwelling plume in concordance to a localized wind maximum (up to $15 \mathrm{~m} . \mathrm{s}^{-1}$ ) 10 to $15 \mathrm{~km}$ offshore. This feature is forced by the extreme land-sea temperature gradient caused by the close vicinity of one the most arid deserts in the world and the cool coastal upwelled waters. This wind pattern is not resolved by QuikSCAT.

[49] In winter, COADS, ROMS and Pathfinder show the same large scale sea surface temperature pattern (Figures 11g, 11h, and 11i). The position and width of the equatorial front in ROMS match Pathfinder observations. But, close to the Peruvian coastline, an upwelling is still present in COADS and Pathfinder; this upwelling is almost absent in the model simulation. The bias in the position of the thermocline might cause this lack of upwelling, since water from above (instead of below) the thermocline could be upwelled. This difference might also be associated with weaknesses in local surface wind forcing. Note that the Paracas upwelling cell is still strong in Pathfinder.

[50] ROMS sea surface temperature is similar to both COADS and Pathfinder in spring (Figures $11 \mathrm{j}, 11 \mathrm{k}$, and 111). It again presents a cold tongue and a large-scale pattern that closely resembles to Pathfinder data.

[51] All this gives us confidence in the model's ability to reproduce surface oceanic patterns with a certain realism. A few biases are still present such as the weakness of upwelling in winter, the too strong upwelling in summer and the absence of the plume near $15^{\circ} \mathrm{S}$.

\subsection{Sea Surface Height Anomalies}

[52] Seasonal sea surface height anomalies (SSH) are presented for our model simulation (averaged from year 3 to 10) and for satellite altimeter data in Figure 12. Altimeter measurements are obtained from high-resolution $\left(1 / 3^{\circ}\right)$ merged TOPEX/Poseidon, ERS-1/-2 and Jason gridded data from 14 October 1992 to 28 January 2004 [Ducet et al., 2000]. The simulated and observed SSH anomalies present some similarities. Two distinct patterns are noticeable.

[53] Firstly, north of $3^{\circ} \mathrm{S}$, a strong seasonal oscillation is present in both the model and observations. It reaches a minimum value of $-9 \mathrm{~cm}$ for the satellite (Figure 12a) and $-7 \mathrm{~cm}$ for the model (Figure 12b) in summer, and a maximum value of $6 \mathrm{~cm}$ for the satellite (Figure 12g) and $5 \mathrm{~cm}$ for the model (Figure 12h) in spring. Although the transition from low values to high values appears to be quite progressive, expanding slowly from fall to spring, the shift from high to low values is extremely sharp in both the model and observations. It occurs between spring and summer (i.e. around December-January). This annual event might be related to the annual peak found in the time variations of the model surface kinetic energy (Figure 3a). Hence, the annual large-scale accelerations in the SEC $\left(2^{\circ} \mathrm{N}\right)$ are reflected in $\mathrm{SSH}$, and the model is able to reproduce this pattern. As mentioned in section 2.3, this regular phenomenon could be related to the Annual El-Niño Current described by Strub et al. [1998].

[54] Secondly, along the Peruvian coastline, one can note another type of oscillation. In winter, during the height of the upwelling season, $\mathrm{SSH}$ is minimum along the coast for both the model (Figure 12h) and observations (Figure 12e). The associated alongshore currents propagate offshore, and in spring the minimum in $\mathrm{SSH}$ is then located at least $600 \mathrm{~km}$ from the coast (Figures $12 \mathrm{~g}$ and $12 \mathrm{~h}$ ). In Summer, the coastal SSH minimum has been replaced by a maximum (Figures 12a and 12b). In fall, the maximum has also moved offshore by about $600 \mathrm{~km}$ (Figures 12c and 12d). Although a few local differences are noticeable, such as smaller scale variations along the coast in altimeter data, the model reproduces this large scale offshore-propagating seasonal pattern. This kind of seasonal offshore propagation of SSH anomalies has been observed in other upwelling systems [Marchesiello et al., 2003] and corresponds to seasonal, wind generated, westward-propagating Rossby waves.

\section{Mesoscale Dynamics}

\subsection{Eddy Kinetic Energy}

[55] As observed in other upwelling system models (see for example Marchesiello et al. [2003] for the California Current System and Penven et al. [2001] for the Benguela Current System), in the absence of synoptic and interannual variability in the surface fluxes, this model is able to generate an intense mesoscale activity through oceanic instability processes. Looking at animations of the model vorticity or sea surface height, one can note that a large number of eddies are generated from the upwelling front and then propagate offshore. The nonseasonal and noninterannual (i.e. by employing the seasonal averages to obtain the anomalies) eddy kinetic energy (EKE) has been computed using the geostrophy from the sea surface height for both the model simulation and the altimeter observations (Figure 13).

Figure 11. Seasonal variations of sea surface temperature $\left[{ }^{\circ} \mathrm{C}\right]$ for the COADS climatology (first column), a climatology derived from Pathfinder AVHRR satellite data (second column) and ROMS model (third column). 
a) Altimeter summer

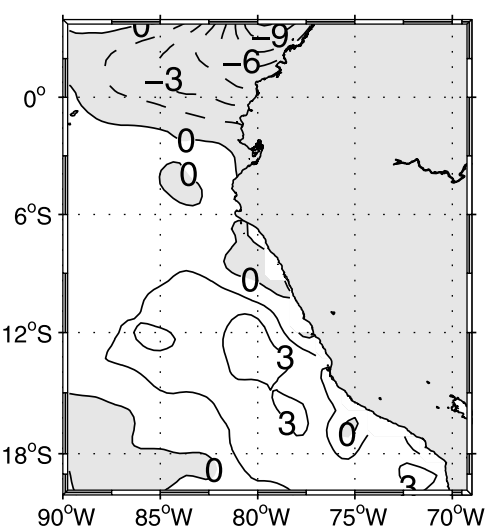

c) Altimeter fall

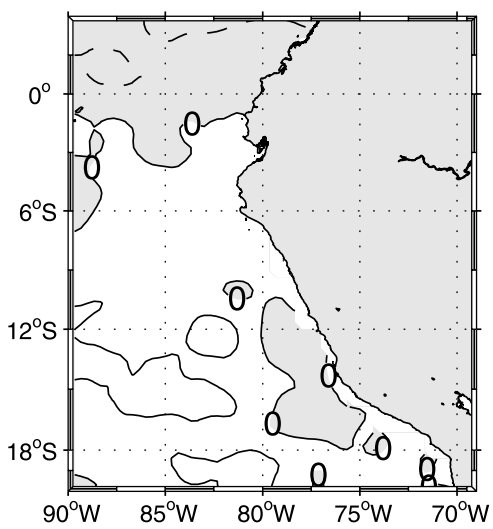

e) Altimeter winter

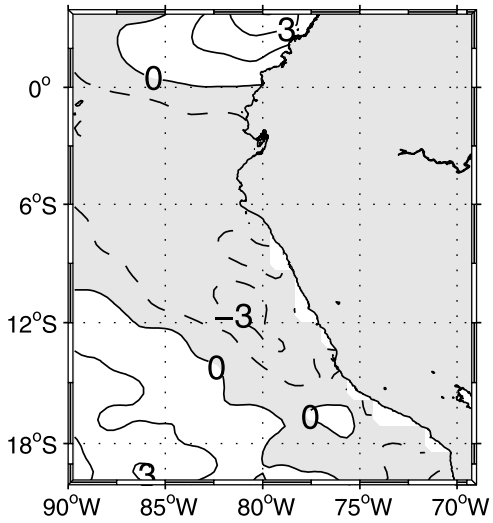

g) Altimeter spring

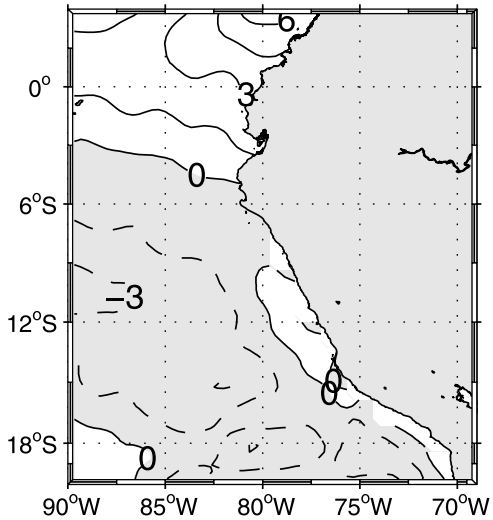

b) ROMS summer

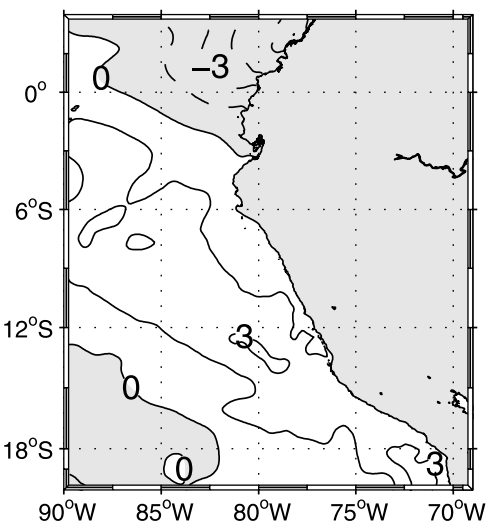

d) ROMS fall

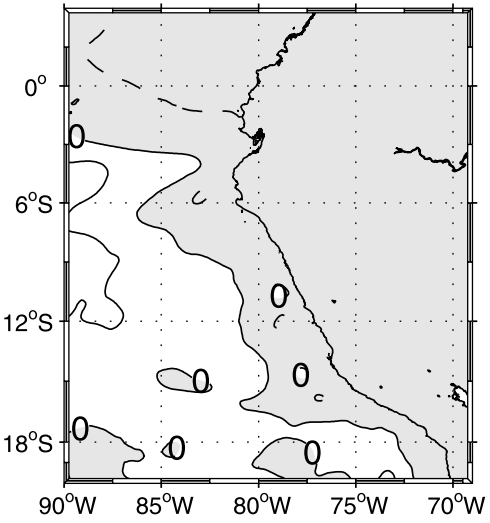

f) ROMS winter

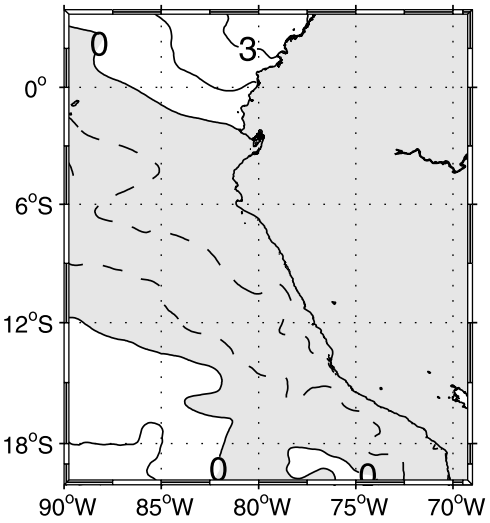

h) ROMS spring

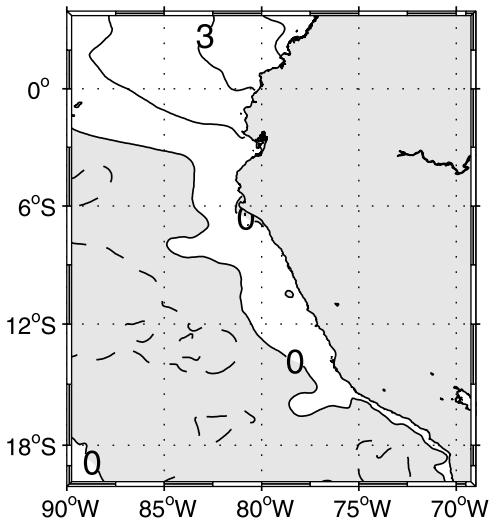

Figure 12. Seasonal mean sea surface height anomalies $[\mathrm{cm}]$ for satellite altimeter and the model simulation. 
a) ROMS $\left[\mathrm{cm}^{2} / \mathrm{s}^{2}\right]$

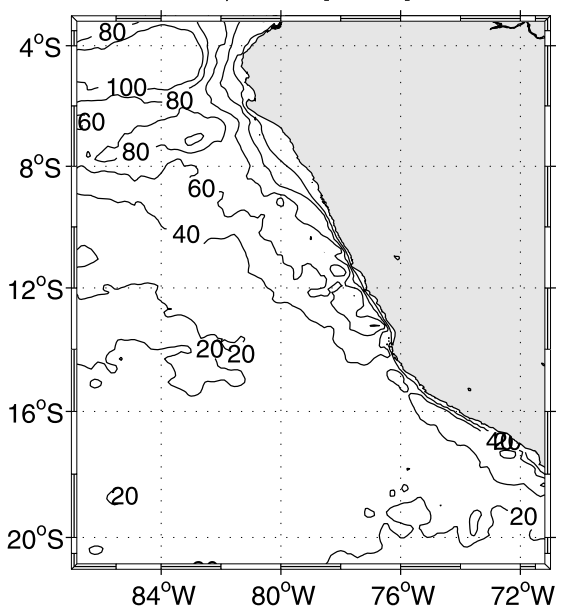

b) Altimeter $\left[\mathrm{cm}^{2} / \mathrm{s}^{2}\right]$

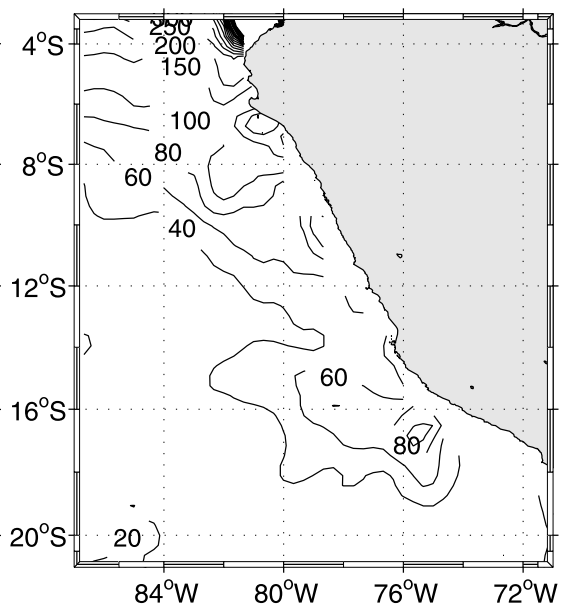

c) Relative difference [\%]

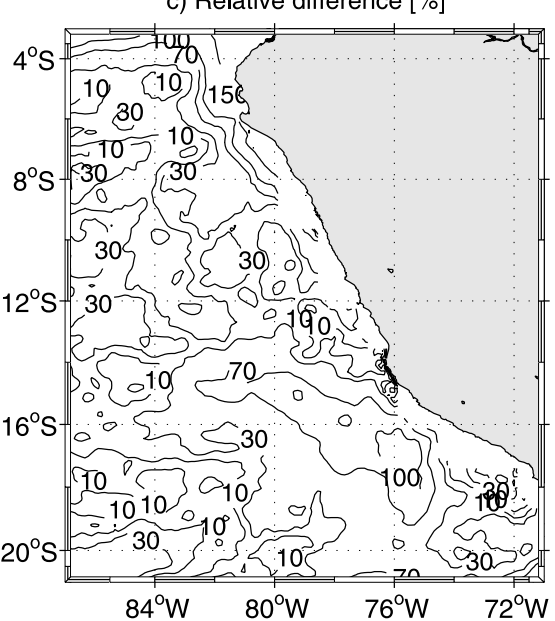

Figure 13. Annual mean surface eddy kinetic energy $\left[\mathrm{cm}^{2} \cdot \mathrm{s}^{-2}\right]$ for the model simulation and satellite altimeter.

[56] For ROMS, the EKE in the PCS is higher at the coast, with values ranging from $40 \mathrm{~cm}^{2} . \mathrm{s}^{-2}$ to $80 \mathrm{~cm}^{2} . \mathrm{s}^{-2}$ (Figure 13a). These values increase further as the equator is approached, for example the EKE attains $100 \mathrm{~cm}^{2} \cdot \mathrm{s}^{-2}$ close to the SECC. The EKE decreases offshore and remains at relatively low levels (below $10 \mathrm{~cm}^{2} . \mathrm{s}^{-2}$ ) in the southwestern part of the model domain. Altimeter EKE follows the same pattern: high values in the upwelling front and close to the equator, and lower values offshore (Figure 13b). There are 3 areas where the difference between model and altimeter EKE is significant: close to the equator, in the southern part of the domain, and in a specific location $\left(17^{\circ} \mathrm{S}-75.5^{\circ} \mathrm{W}\right)$ where the EKE values are higher in the observations. In the tropical region, variability is mostly associated with coastal trapped waves of large-scale equatorial origin [Brink et al., 1983]. Since all nonseasonal variations have been filtered in the large-scale oceanic data employed to force the model boundaries, an important source of variability is missing north of $5^{\circ} \mathrm{S}$. South of $18^{\circ} \mathrm{S}$ and west of $76^{\circ} \mathrm{W}$, modeled EKE is relatively low in comparison to observations. Three reasons can explain this discrepancy: eddies coming from the southern part of the Humboldt system are not represented in this simulation; the POC and its variations are not correctly reproduced; and since the observed values in EKE are quite low, the synoptic wind variations might have a relatively greater effect. The third area of model/data EKE discrepancy is located offshore of Nazca $\left(\sim 17^{\circ} \mathrm{S}-75.5^{\circ} \mathrm{W}\right)$. In this area, altimeter data present a maximum in variability which is not seen in the model solution. The Pisco - San Juan upwelling plume can be an important source of eddies for the area and it would necessitate further invertigation.

[57] In the central PCS (i.e. in a band situated between latitudes $15^{\circ} \mathrm{S}$ and $7^{\circ} \mathrm{S}$ ), the model is able to produce a level of EKE only $10 \%$ to $30 \%$ lower than the observations (Figure 13c). This accomplishment has been achieved in the absence of synoptic variability in the model boundary conditions (surface and lateral). Hence, for the central PCS, at least $70 \%$ to $90 \%$ of the nonseasonal, noninterannual surface EKE (associated with geostrophic currents) can be explained by locally generated turbulent processes. One can note the progress achieved since the work of Stammer and Boening [1992]. For the Atlantic Ocean, they found that the variability in the WOCE model $\left(1 / 3^{\circ} \times 2 / 5^{\circ}\right.$ resolution $)$ was systematically up to 4 times lower than GEOSAT observations. Even if the level of eddy kinetic energy in our model is slightly too low, Figure 13 gives confidence for the use of the model outputs to study, at least qualitatively, the mesoscale dynamics in the PCS with a relatively realistic level of energy.

\subsection{Eddy Length Scales and Kinetic Energy Spectra}

[58] As an illustration of the turbulent character of the simulation, the vertical component of vorticity and the Okubo-Weiss parameter $(\lambda)$ at $20 \mathrm{~m}$ depth are presented for 21 June of model year 8 on Figure 14. The Okubo-Weiss parameter takes the form:

$$
\lambda=\left(\frac{\partial u}{\partial x}-\frac{\partial v}{\partial y}\right)^{2}+\left(\frac{\partial v}{\partial x}+\frac{\partial u}{\partial y}\right)^{2}-\left(\frac{\partial v}{\partial x}-\frac{\partial u}{\partial y}\right)^{2}
$$

where $\mathrm{u}$ and $\mathrm{v}$ are the horizontal velocity components, and $\mathrm{x}$ and $\mathrm{y}$ are the horizontal coordinates. The first 2 terms of equation (5) represent the deformation and the last term, the relative vorticity. Therefore, if $\lambda$ is positive, the deformation dominates, otherwise if $\lambda$ is negative, the relative vorticity dominates. The Okubo Weiss parameter thus helps to detect the boundary of the eddies. Eddies are characterized by a strong rotation in their center, and a strong deformation in the periphery; therefore they can be represented by patches of negative values of Okubo-Weiss parameter surrounded by positive rings.

[59] The snapshot of subsurface vorticity (Figure 14a) shows a succession of cyclones and anticyclones which are generated at the upwelling front. They appear more energetic at the shore, in agreement with Figure 13. In the case of geostrophic turbulence, if the spatial variations in the Rossby radius of deformation are not negligible (e.g. close to the equator), Theiss [2004] has established the presence of a critical latitude $\left(\phi_{c}\right)$. On the poleward side of $\phi_{c}$, the turbulence is isotropic; while on the equatorward side, alternating zonal jets dominate the flow (see 

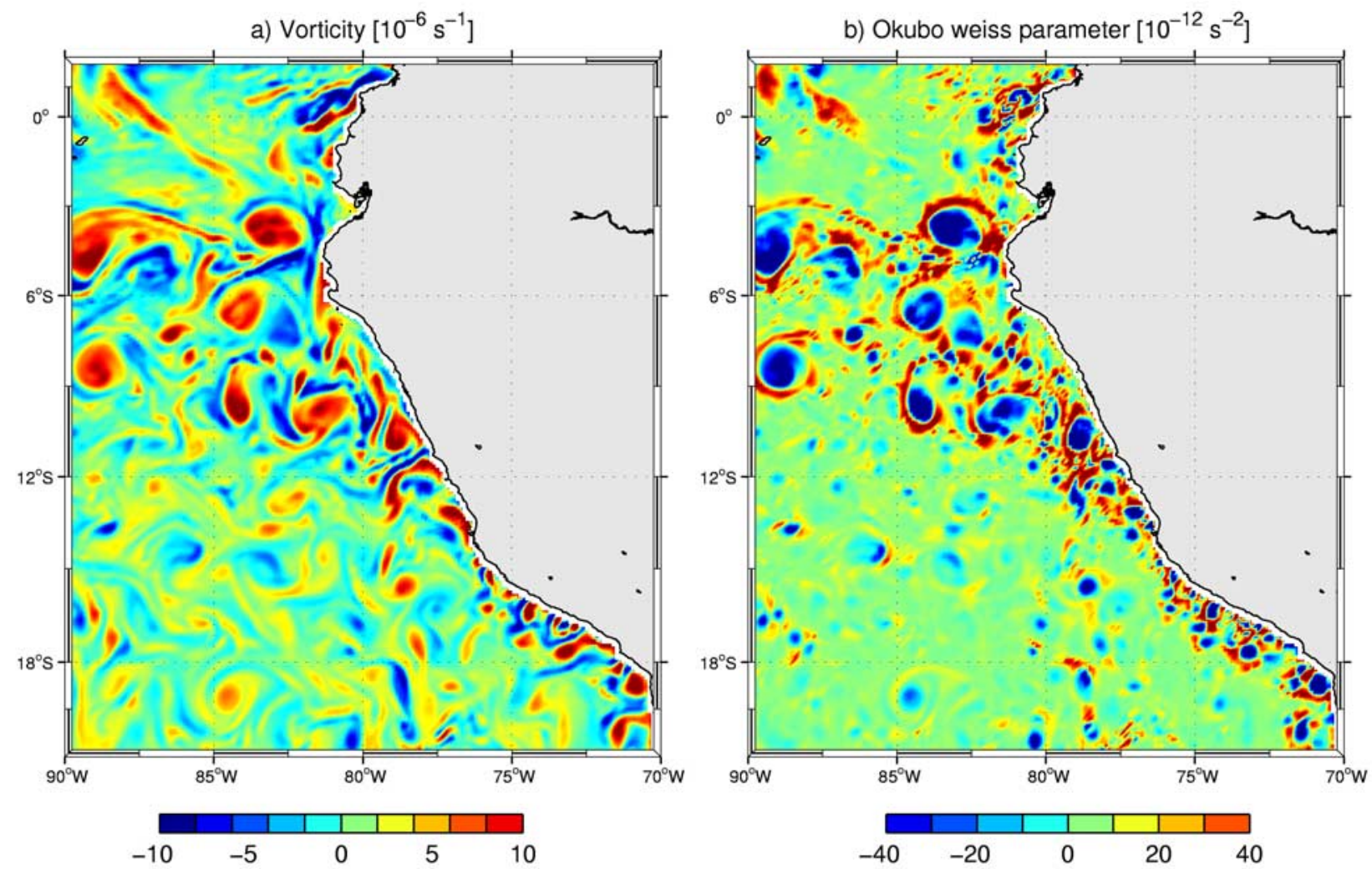

Figure 14. Vorticity $\left[10^{-6} \mathrm{~s}^{-1}\right]$ and Okubo-Weiss parameter $\left[10^{-12} \mathrm{~s}^{-2}\right]$ at $20 \mathrm{~m}$ depth for the $21 \mathrm{June}$ of model year 8 .

Figure 8 in Theiss [2004]). In our simulation, a distinct transition occurs between a turbulent flow, south of $3^{\circ} \mathrm{S}$; and the presence of large scale equatorial currents in the north (Figure 14a). In the PCS, eddies are clearly separated in the image of the Okubo Weiss parameter (Figure 14b). Looking more closely on Figure 14b, it appears that the eddies seem, in general, larger in the northern part of the domain.

[60] To verify this impression, the characteristic eddy length scales were calculated in a more rigorous manner. Stammer and Boening [1992] analysed oceanic eddy characteristics from altimeter measurements. From autocorrelation functions derived from GEOSAT data in $10^{\circ} \times$ $10^{\circ}$ subdomains in the Atlantic Ocean, they computed the lag of the first zero crossing $\left(L_{0}\right)$, the linear integral scales $\left(L_{1}\right)$ and the quadratic integral scales $\left(L_{2}\right)$. They found a linear relation between $L_{0}$ and the first Rossby radius of deformation outside the equatorial region $\left(10^{\circ} \mathrm{S}-10^{\circ} \mathrm{N}\right)$. Stammer [1997] extended the same analysis to the global Ocean. In our case, the autocorrelation functions have been calculated from surface current anomalies in $2^{\circ} \times 2^{\circ}$ boxes centered on each point of a $0.5^{\circ}$ resolution grid. They have been averaged from year 3 to year 10 :

$$
\begin{aligned}
f_{X_{0}, Y_{0}}(d)= & \left\langle\left\langle\int_{X_{0}-1}^{X_{0}+1} v^{\prime}(x) v^{\prime}(x+d) d x\right\rangle_{y}\right. \\
& \left.+\left\langle\int_{Y_{0}-1}^{Y_{0}+1} u^{\prime}(y) u^{\prime}(y+d) d y\right\rangle_{x}\right\rangle_{t}
\end{aligned}
$$

where $\mathrm{f}_{X_{0}, Y_{0}}$ is the autocorrelation function for the box centered at longitude $X_{0}$ and latitude $Y_{0}, u^{\prime}$ and $v^{\prime}$ are surface current horizontal anomaly components, and $d$ is a distance. $L_{0}$ is presented on Figure 15. This representation shows larger eddies in the northern part of the model domain (almost by a factor of 2) than in the south. We can also note a progressive increase in eddy sizes when moving from the coast to offshore.

[61] To validate this approach, another method was used to calculate the eddy characteristics. From the Okubo Weiss parameter described above, it is also possible to systematically follow the eddies. An eddy tracking algorithm has been developed following this procedure:

[62] 1. Compute the Okubo-Weiss parameter at $20 \mathrm{~m}$ depth. Spatially smooth it by applying a Hanning filter several times in order to keep only the significant structures.

[63] 2. Detect the local minimums (i.e. every grid point which presents a value that is below its eight surrounding points). These should correspond to eddy centers.

[64] 3. For each local minimum, compute several relevant eddy properties: the position of the center, the radius (i.e. the minimum distance between each local minimum and where the Okubo Weiss parameter changes its sign) and the mean relative vorticity (i.e. the relative vorticy averaged over the eddy radius).

[65] 4. Compute a generalized nondimensional distance $(X)$ between the eddies detected during two successive time steps. For each eddy $\left(e_{1}\right)$ of the first time step and for each eddy $\left(e_{2}\right)$ of the second time step, $X_{e_{1}, e_{2}}$ is 
a) $\mathrm{L}_{0}[\mathrm{~km}]$

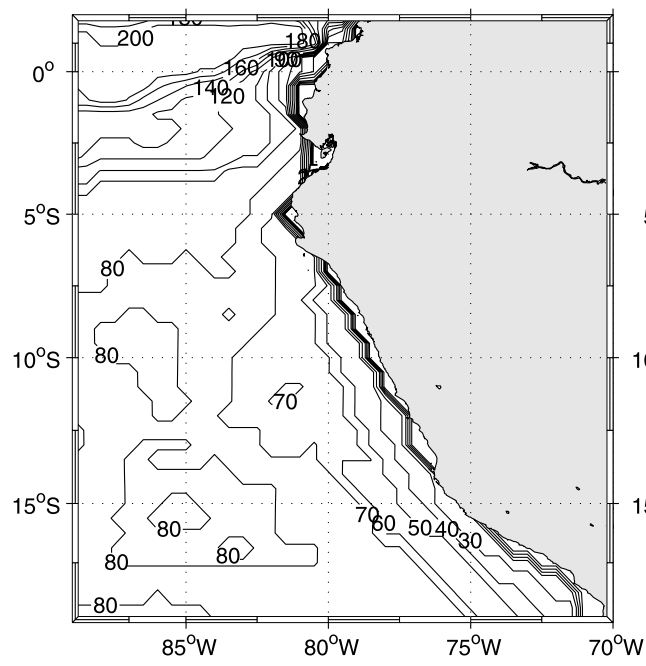

b) Average eddy diameters [km]

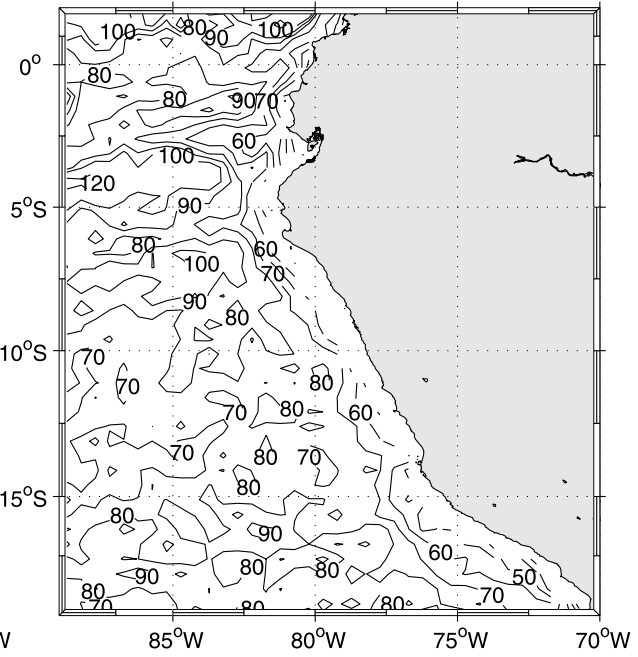

Figure 15. (a) $L_{0}[\mathrm{~km}]$, the zero-crossing distance of transverse velocity autocorrelation functions. (b) Average eddy diameters $[\mathrm{km}]$.

defined as an Euclidean distance in a nondimensional property space:

$$
X_{e_{1}, e_{2}}=\sqrt{\left(\frac{\Delta X}{X_{0}}\right)^{2}+\left(\frac{\Delta R}{R_{0}}\right)^{2}+\left(\frac{\Delta \xi}{\xi_{0}}\right)^{2}}
$$

where $\Delta X$ is the spatial distance between $e_{1}$ and $e_{2}, \Delta R$ is the variation of diameter between $e_{1}$ and $e_{2}$, and $\Delta \xi$ is the variation of vorticity between $e_{1}$ and $e_{2} . X_{0}$ is a characteristic length scale $(100 \mathrm{~km}), R_{0}$ is a characteristic radius $(50 \mathrm{~km})$ and $\xi_{0}$ is a characteristic vorticity $\left(10^{-6} \mathrm{~s}^{-1}\right)$.

[66] 5. Select the eddy pair $\left(e_{1}, e_{2}\right)$ that minimize $X_{e_{1}, e_{2}}$ to be the same eddy that is tracked from the first time step to the second time step.

[67] $X$ measures the degree of dissimilarity between two eddies. Hence, it helps to discriminate between cyclones and anticyclones and between large and small eddies. Other eddy properties could be added into $X$ calculation such as potential vorticity, temperature or salinity.

[68] This algorithm has been applied to the model outputs, and the resulting mean eddy diameters $\left(D_{e}\right)$ are presented on Figure $15 \mathrm{~b}$. South of $3^{\circ} \mathrm{S}, D_{e}$ is in agreement with $L_{0}$. It is minimum at the coast, and increases towards the equator. North of $3^{\circ} \mathrm{S}$ (i.e. the critical latitude observed on Figure 14), $D_{e}$ undergoes a marked decrease. In this area, $L_{0}$ and $D_{e}$ are in total disagreement. This strengthens the point that there is a sharp bifurcation in eddy dynamics in the PCS around $3^{\circ} \mathrm{S}$. Outside an equatorial band, $L_{0}$ appears to be a reliable measure for the mean eddy diameters.

[69] To further explore the turbulent aspects in the PCS, one-dimensional kinetic energy spectra for the surface currents are computed (Figure 16). They are spatially averaged on $2^{\circ}$ wide latitude bands, centered at the latitudes: $17.5^{\circ} \mathrm{S}$, $15^{\circ} \mathrm{S}, 12.5^{\circ} \mathrm{S}, 10^{\circ} \mathrm{S}, 7.5^{\circ} \mathrm{S}$ and $5^{\circ} \mathrm{S}$. They are also temporally averaged from year 3 to year 10. In the case of geostrophic turbulence, the predicted energy spectra should be characterized by a $k^{-3}$ power law for the direct enstrophy cascade (at wave numbers that are larger than the forcing wave numbers), and a $k^{-5 / 3}$ inverse energy cascade spectrum (at wave numbers that are smaller than the forcing wave numbers) [Charney, 1971]. In the presence of $\beta$ effect, the inverse cascade towards the large scales is halted when the scales are large enough for Rossby waves to be able to radiate turbulent energy [Rhines, 1975].

[70] For each latitude band, the modeled energy spectra obey almost rigorously the theoretical predictions, presenting well-developed energy and enstrophy inertial ranges. The energy injection length scales can be deducted from the marked change in slope in the spectra (e.g. the intersections between the $k^{-3}$ and $k^{-5 / 3}$ lines on Figure 16). One can note that the injection length scales are larger in the northern part of the model domain. For each spectrum on Figure 16 a cutoff scale is defined where the curve departs from the $k^{-5 / 3}$ power low (i.e. where the red cascade is halted). Although it slightly increases towards the north, this cutoff scale does not present important variations around a mean value of about $400 \mathrm{~km}$. The Rhines scale takes the form: $\sqrt{\frac{U}{\beta}}$, where $U$ is a characteristic root mean square velocity [Rhines, 1975]. Using the model surface root mean square velocities we obtained a Rhines scale of the order of $70 \mathrm{~km}$. Thus, It has not been possible to relate the model cutoff scale to the theoretical cutoff Rhines scale.

[71] Since the injection length scale increases towards the equator, while the cutoff scale varies by a much smaller amount; at $5^{\circ} \mathrm{S}$, the energy cascade inertial region almost totally vanishes. This behavior is consistent with the findings of Theiss [2004]: in the quasigeostrophic framework, the critical latitude which marks the transition from an isotropic turbulent flow to alternating zonal currents is the latitude where the Rossby radius of deformation equals the cutoff Rhines scale. In our case, the injection length scale reaches the cutoff scale around $3^{\circ} \mathrm{S}$. This might be an explanation for the sharp transition observed on Figure 14. However, at $3^{\circ} \mathrm{S}$ we lie within the equatorial band of twice the equatorial deformation radius $(\sim 230 \mathrm{~km})$ [Chelton et al., 1998], degrading the validity of the formalism used by Theiss [2004]. 
a) $17.5^{\circ} \mathrm{S}$

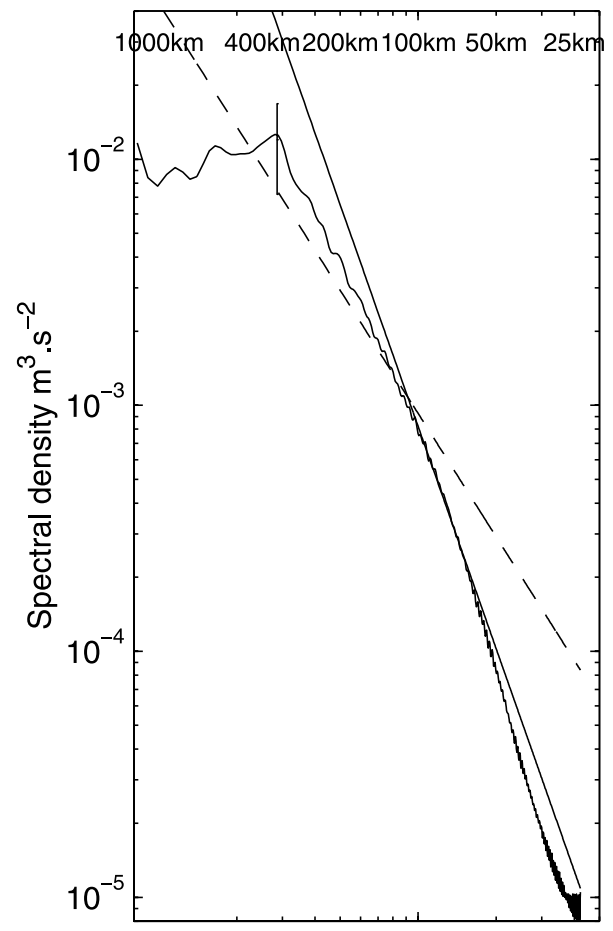

d) $10^{\circ} \mathrm{S}$

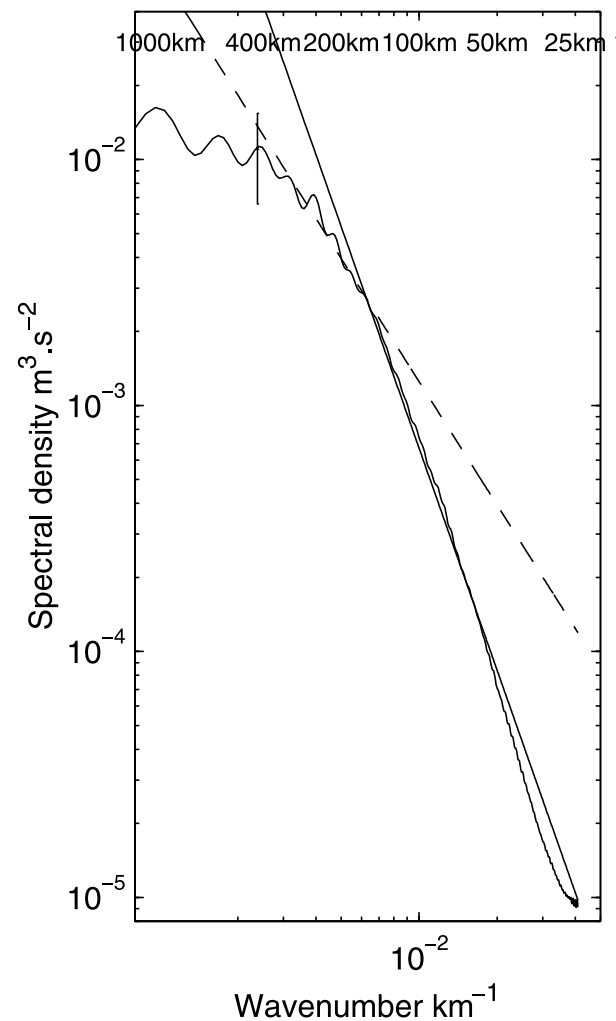

b) $15^{\circ} \mathrm{S}$

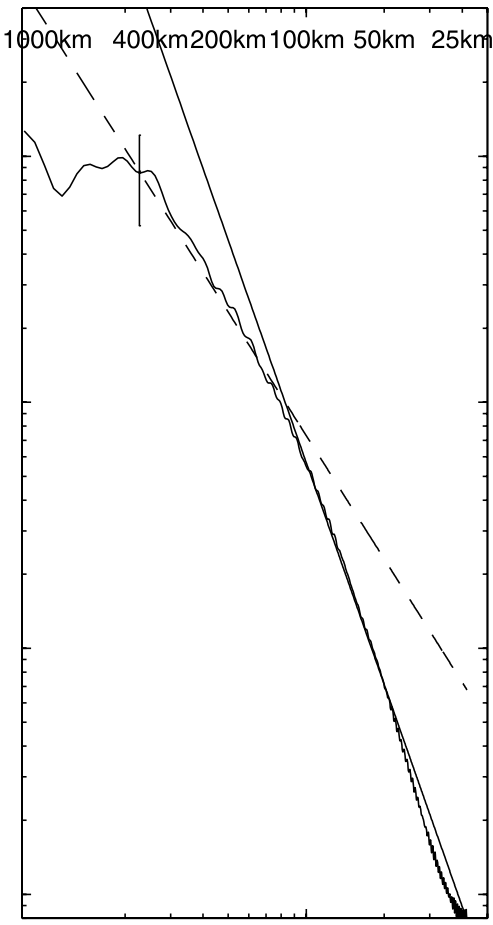

e) $7.5^{\circ} \mathrm{S}$

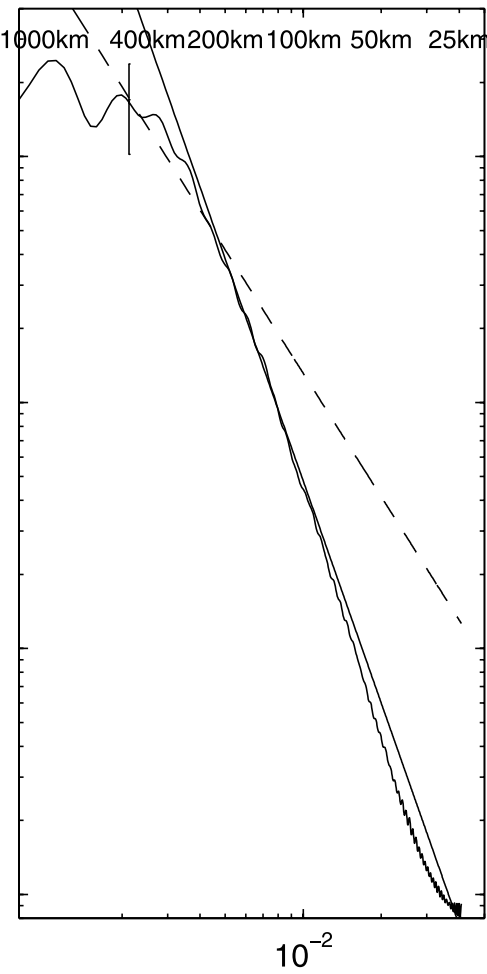

Wavenumber $\mathrm{km}^{-1}$ c) $12.5^{\circ} \mathrm{S}$

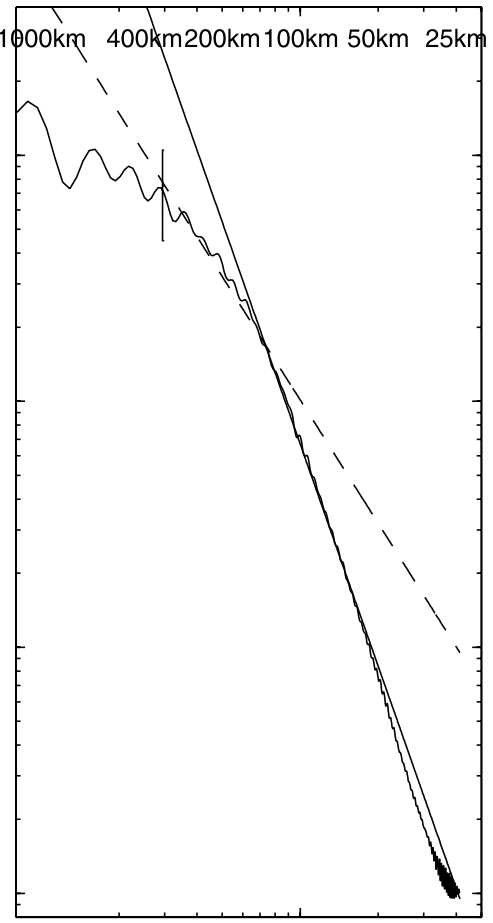

f) $5{ }^{\circ} \mathrm{S}$

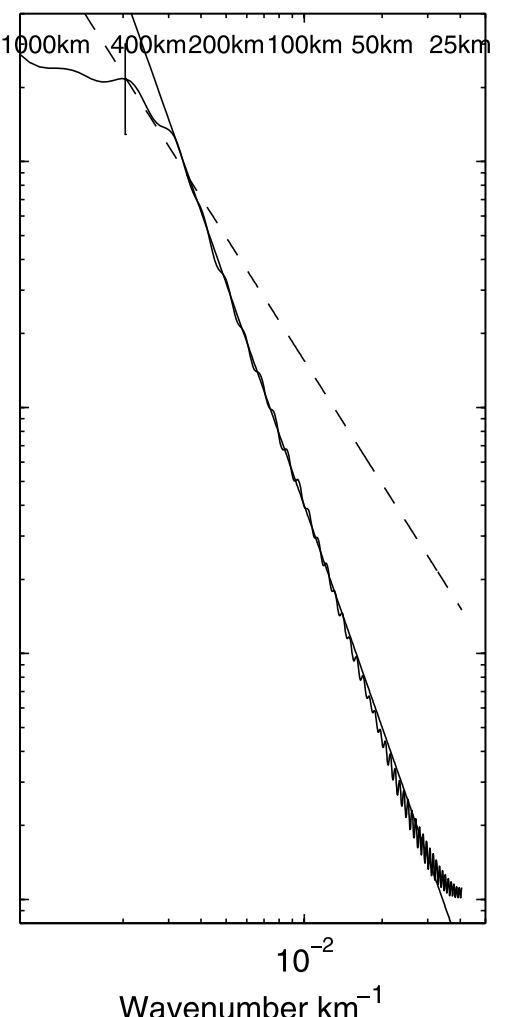

Figure 16. Kinetic energy spectra $\left[\mathrm{m}^{3} \cdot \mathrm{s}^{-2}\right]$ as a function of the wavelengths $\left[\mathrm{km}^{-1}\right]$, centered at different latitude bands: (a) $17.5^{\circ} \mathrm{S}$, (b) $15^{\circ} \mathrm{S}$, (c) $12.5^{\circ} \mathrm{S}$, (d) $10^{\circ} \mathrm{S}$, (e) $7.5^{\circ} \mathrm{S}$, and (f) $5^{\circ} \mathrm{S}$. The straight line represents a $k^{-3}$ power law, and the dashed line represents a $k^{-5 / 3}$ power law. The vertical lines indicate the cutoff scales. 


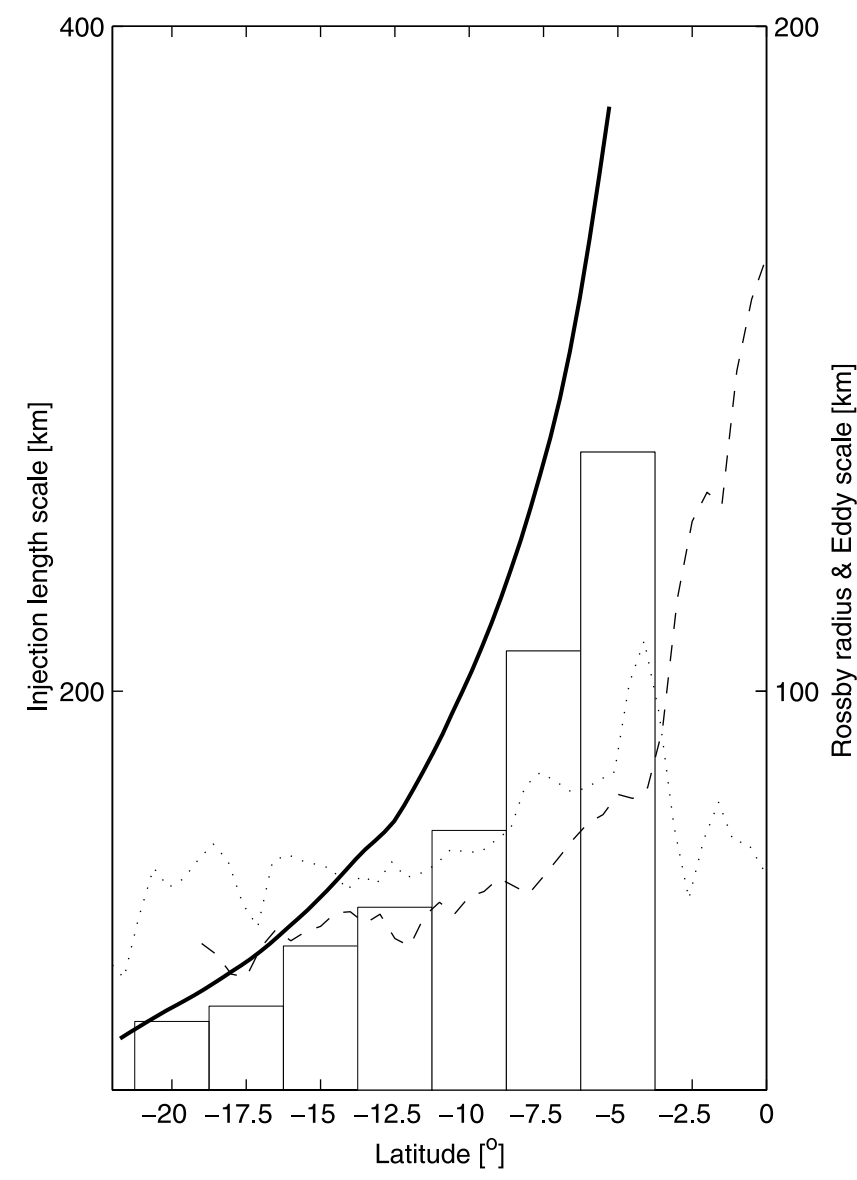

Figure 17. The first Rossby radius of deformation [km] (continuous line), the eddy length scale $[\mathrm{km}]$ (dashed line), and the mean eddy diameters (dotted line) averaged on the first $1000 \mathrm{~km}$ from the shore, and the energy injection scales $[\mathrm{km}]$ (bars). Note that the scale used for the energy injection scales is twice the one used for the other variables.

[72] There are two major differences between our model and theoretical results. Firstly, idealised experiments show an equatorward energy cascade through the movement of eddies towards the equator. By tracking the eddies one by one, it has been possible to derive their average displacements. In out model, south of $12^{\circ} \mathrm{S}$, eddies are moving straight offshore, while, between $5^{\circ} \mathrm{S}$ and $12^{\circ} \mathrm{S}$, they present a southwestward movement. Secondly, while Theiss [2004] has detected a majority of cyclones, in our experiment, in the PCS, there is evidence for a larger population of anticylones.

[73] To summarize, the eddy length scale $L_{0}$ and the mean eddy diameters $\left(D_{e}\right)$ (both averaged in the first $1000 \mathrm{~km}$ from coast), the energy injection length scales, and the Rossby radius of deformation are presented together in Figure 17. South of $3^{\circ} \mathrm{S}, D_{e}$ and $L_{0}$ are in relative agreement. They increase towards the north from about $40 \mathrm{~km}$ to more than $100 \mathrm{~km}$. As explained by Stammer and Boening [1992], outside of the equatorial region, the eddy characteristic length scale follows the variations of the Rossby radius of deformation. The relation between the Rossby radius of deformation and the energy injection length scale is obvious. Because the first Rossby radius of deformation is the fastest growing mode for the baroclinic instability, this relation supports the agreement that baroclinic instability is the predominent eddy generation mechanism in the PCS.

\section{Conclusion}

[74] In this paper, we have presented the results of a high resolution simulation for the PCS, based on the ROMS Ocean model. The focus was on the mean circulation, the seasonal cycle and the mesoscale processes.

[75] After a short spin-up, the model solution does not present any significant temporal drift and is representative of the known dynamics in this region. Since this is not an operational simulation, the evaluation of the model skills is done by a general comparison of the averaged circulation, the mean baroclinic structure, and the seasonal cycle that which has been published in literature and to annual or seasonal climatologies.

[76] The major known currents in the PCS are rendered quite accurately. The model is able to reproduce the coastal dynamics of the PCC which flows equatorward in a band of $100 \mathrm{~km}$ from the shore. The modeled PCUC is at a correct location, with a correct vertical extension, and with currents situated in the range of the observations. The upper part of the current is extremely close to the Ocean surface; and due to a strong cyclonic wind stress curl, might even outcrop as a counter current. The bottom part appears to follow $\frac{f}{H}$ isolines, causing the deepening of the PCUC as it flows away from the equator. The model produces a PCCC which runs towards the south and veers towards the west between $15^{\circ} \mathrm{S}$ and $18^{\circ} \mathrm{S}$. The connection between the SECC, the PCCC and the PCUC is in agreement with the published circulation diagrams. The PCCC appears to be a large scale southward flow, directly forced by wind stress curl, which is cyclonic almost over the whole PCS (at least north of $15^{\circ} \mathrm{S}$ ). In the model simulation, the PCCC is clearly distinct from the outcropping of the PCUC.

[77] The vertical baroclinic structure for the central PCS presents a very sharp thermocline. Although this feature is almost absent in the OGCM used as initial and boundary conditions, our regional model is able to restore part of it, reducing the maximum bias from $3^{\circ} \mathrm{C}$ to $1.5^{\circ} \mathrm{C}$. For the case of salinity, the model does not depart more than 0.12 PSU from the observations.

[78] For the SST, although a few biases are noticeable, our model is able to produce the upwelling front, the cold water tongue which extends toward the equator and the equatorial front in a realistic manner. In the case of SSH, the model is quite accurate in its representation of the annual variations of the SEC (which generate a strong annual oscillation at the equator) and the seasonal changes in upwelling which propagate offshore from the Peruvian coast.

[79] The PCS hosts a significant eddy activity associated with local instability processes. For the central PCS, the model EKE is comparable with the observations. Due to large variations in the Rossby radius of deformation, the modeled eddies are larger in the northern part of the domain. South of $3^{\circ} \mathrm{S}$, the eddy characteristic length scales $L_{0}$ are in agreement with the mean eddy diameters $D_{e}$ estimated with a eddy tracking algorithm. They follow the equatorward increase in the Rossby radius of deformation. The injection length scales, derived from the energy spectra, strongly 
correlate to the Rossby radius of deformation, confirming the predominant role of baroclinic instability. At $3^{\circ} \mathrm{S}$, the dynamics shift from a turbulent regime to zonal currents at much larger scales as the injection length scale reaches the cutoff scale.

[80] The model also presents some weaknesses. Firstly, due to limitations in domain size or boundary conditions, it fails to produce a significant POC offshore of the system. Secondly, although the model reduces the bias induced by the initial and the boundary conditions, there is still a weakness in the representation of the subsurface thermocline. Thirdly, the model does not generate the Paracas upwelling plume and presents a very weak upwelling signature in austral winter. The first two points seem to be related to the large scale structure of the OGCM employed for the initial and boundary conditions. In the near future, availability of other OGCMs will allow us to perform a sensitivity analysis on the boundary conditions. Moreover, for the California Current System, Capet et al. [2004] have recently demonstrated that the near shore structure of the wind stress might be preponderant for upwelling. Hence, to address the third point, it will be necessary to have access to the fine structure of the wind stress in a band of $50 \mathrm{~km}$ close to the shore.

[81] To summarize, the PCS differentiates itself from the other upwelling systems on 3 major points. Firstly, the closeness of the equator induces a connection between the upwelling system and the large scale equatorial currents, and implies changes in the Rossby radius of deformation of almost one order of magnitude over the length of the system. Secondly, a very shallow thermocline should make the upwelling system particularly dependant of its deepening when Kelvin waves propagates from the equator. Thirdly, the presence of cyclonic wind stress curl throughout the domain induces a dominance of poleward flow below a shallow surface layer.

[82] In future work, this dynamical model will be used as a tool to address: intraseasonal and interannual variability related to ENSO, coupling between dynamics and biogeochemical cycles, and dynamical coastal processes related to fish recruitement strategies.

[83] Acknowledgments. QuickSCAT data are obtained from the NASA/NOAA sponsored data system Seaflux, at JPL through the courtesy of W. T. Liu and W. Tang. The global topography database is obtained from the Scripps Institution of Oceanography. OCCAM data are obtained from the Southampton Oceanography Centre. The AVHRR Oceans Pathfinder SST data were obtained from the Physical Oceanography Distributed Active Archive Center (PO.DAAC) at the NASA Jet Propulsion Laboratory, Pasadena, California (http://podaac.jpl.nasa.gov). The altimeter products have been produced by the CLS Space Oceanography Division. The World Ocean Atlas 2001 is obtained from the National Oceanographic Data Center. We thank Nicolette Chang for her assistance in correcting the manuscript.

\section{References}

Beckmann, A., and D. B. Haidvogel (1993), Numerical simulation of flow around a tall isolated seamount. part I: Problem formulation and model accuracy, J. Phys. Oceanogr., 23, 1736-1753.

Brink, K. H. (1982), A comparison of long coastal trapped wave theory with observations off Peru, J. Phys. Oceanogr., 12.

Brink, K. H., D. Halpern, A. Huyer, and R. L. Smith (1983), The physical environment of the Peruvian upwelling system, Prog. Oceanogr., 12, $185-305$.

Capet, X. J., P. Marchesiello, and J. C. McWilliams (2004), Upwelling response to coastal wind profiles, Geophys. Res. Lett., 31, L13311, doi:10.1029/2004GL020123.
Casey, K. S., and P. Cornillon (1999), A comparison of satellite and in situ based sea surface temperature climatologies, J. Clim., 12, $1848-$ 1863.

Charney, J. G. (1971), Geostrophic turbulence, J. Atmos. Sci., 28, $1087-$ 1095.

Chavez, F. P. (1995), A comparison of ship and satellite chlorophyll from California and Peru, J. Geophys. Res., 100, 24,855-24,862.

Chelton, D. B., R. A. deSzoeke, M. G. Schlax, K. E. Naggar, and N. Siwertz (1998), Geographical variability of the first-baroclinic rossby radius of deformation, J. Phys. Oceanogr., 28, 433-460.

Clarke, A. J. (1989), Theoretical understanding of eastern ocean boundary poleward undercurrents, in Coastal Estuarine Studies, vol. 34, edited by S. Neshyba, C. N. K. Mooers, R. L. Smith, and R. T. Barber, pp. 26-39, Springer, New York.

Conkright, M. E., R. A. Locarnini, H. E. Garcia, T. D. O. Brien, T. P. Boyer, C. Stephens, and J. I. Antonov (2002), World ocean atlas 2001: Objective analyses, data statistics, and figures, CD-ROM documentation, technical report, Natl. Oceanogr. Data Cent., Silver Spring, Md

Cucalon, E. (1987), Oceanic variability off Ecuador associated with an El Niño event in 1982-1983, J. Geophys. Res., 92, 14,309-14,322.

Da Silva, A. M., C. C. Young, and S. Levitus (1994), Atlas of surface marine data 1994, vol. 1, Algorithms and procedures, technical report, Natl. Oceanogr. and Atmos. Admin., Silver, Spring, Md.

Ducet, N., P. Y. L. Traon, and G. Reverdin (2000), Global high-resolution mapping of ocean circulation from TOPEX/Poseidon and ERS-1 and -2, J. Geophys. Res., 105, 19,477-19,498.

Fiedler, P. C. (1994), Seasonal and interannual variability of coastal zone color scanner phytoplankton pigments and winds in the eastern Pacific, J. Geophys. Res., 99, 18,371-18,384.

Fonseca, T. R. (1989), An overview of the poleward undercurrent and upwelling along the Chilean coast, in Poleward Flows Along Eastern Ocean Boundaries, vol. 34, edited by S. J. Neshyba, C. N. K. Mooers, R. L. Smith, and R. T. Barber, pp. 203-218, Springer, New York.

Gunther, E. R. (1936), A report on oceanographic investigations in the Peru Coastal Current, Discovery Rep., 13, 107-276.

Haidvogel, D. B., and A. Beckmann (1999), Numerical Ocean Circulation Modeling, vol. 2, Series on Environmental Science and Management, Imperial Coll. Press, London.

Hill, A. E., B. M. Hickey, F. A. Shillington, P. T. Strub, K. H. Brink, E. D. Barton, and A. C. Thomas (1998), Eastern Ocean boundaries, in The Sea, vol. 11, edited by A. R. Robinson and K. H. Brink, pp. 29-67, John Wiley, Hoboken, N. J.

Huyer, A. (1980), The offshore structure and subsurface expression of sea level variations off Peru, 1976-1977, J. Phys. Oceanogrr., 10, $1755-1768$

Huyer, A., M. Knoll, T. Paluzkiewicz, and R. L. Smith (1991), The Peru Undercurrent: A study in variability, Deep Sea Res., 39, 247-279.

Kindle, J. C., R. M. Hodur, S. deRada, J. D. Paduan, L. K. Rosenfeld, and F. Q. Chavez (2002), A COAMPS reanalysis for the eastern Pacific: Properties of the diurnal sea breeze along the central California coast, Geophys. Res. Lett., 29(24), 2203, doi:10.1029/2002GL015566.

Large, W. G., J. C. McWilliams, and S. C. Doney (1994), Oceanic vertical mixing: A review and a model with a nonlocal boundary layer parameterization, Rev. Geophys., 32, 363-403.

Lee, M. M., A. C. Coward, and A. J. G. Nurser (2002), Spurious diapycnal mixing of the deep waters in an eddy-permitting global ocean model, J. Phys. Oceanogr., 32, 1522-1535.

Liu, W. T., W. Tang, and P. S. Polito (1998), Nasa scatterometer provides global ocean-surface wind fields with more structures than numerical weather prediction, Geophys. Res. Lett., 25, 761-764.

Lukas, R. (1986), The termination of the equatorial undercurrent in the eastern Pacific, Prog. Oceanogr., 16, 63-90.

Marchesiello, P., J. C. McWilliams, and A. Shchepetkin (2001), Open boundary condition for long-term integration of regional oceanic models, Ocean Modell., 3, 1-21.

Marchesiello, P., J. C. McWilliams, and A. Shchepetkin (2003), Equilibrium structure and dynamics of the California Current System, J. Phys. Oceanogr., 33, 753-783

Marchesiello, P., S. Herbette, L. Nykjaer, and C. Roy (2004), Eddy-driven dispersion processes in the Canary Current upwelling system: Comparison with the California system, Globec Int. Newsl., 10, 5-7.

McCreary, J. P. (1981), A linear stratified ocean model of the coastal undercurrent, Phil. Trans. R. Soc. London, Ser. A, 302, 385-413.

McCreary, J. P., and S.-Y. Chao (1985), Three-dimensional shelf circulation along an eastern ocean boundary, J. Mar. Res., 43, 13-36.

Moody, G. L., D. V. Stuart, A. I. Watson, and M. M. Nanney (1981), Seasurface temperature and winds during JOINT II: Part I mean conditions, in Coastal Upwelling, edited by F. A. Richards, pp. 21-31, AGU, Washington, D. C. 
Penven, P. (2003), ROMSTOOLS user's guide, technical report, Inst. de Rech. pour le Dév., Paris, France. (Available at http://www.brest.ird.fr/ roms_tools)

Penven, P., C. Roy, J. R. E. Lutjeharms, A. Colin de Verdière, A. Johnson, F. Shillington, P. Fréon, and G. Brundrit (2001), A regional hydrodynamic model of the Southern Benguela, S. Afr. J. Sci., 97, 472-476.

Pizarro, O. (1999), Low frequency fluctuations in the eastern boundary current off South America: Remote and local forcing, Ph.D. thesis, pp. 1377-1398, Dep. of Oceanogr., Goteborg.

Preller, R., and J. J. O'Brien (1980), The influence of bottom topography on upwelling off Peru, J. Phys. Oceanogr., 10, 1377-1398.

Rhines, P. B. (1975), Waves and turbulence on a $\beta$ plane, J. Fluid Mech., $69,417-443$.

Saunders, P. M., A. C. Coward, and B. A. de Cuevas (1999), Circulation of the Pacific Ocean seen in a global ocean model (OCCAM), J. Geophys. Res., 104, 18,281-18,299.

Shaffer, G., O. Pizarro, L. Djurfeldt, S. Salinas, and J. Ruttlant (1997), Circulation and low-frequency variability near the Chilean coast: Remotely forced fluctuations during the 1991-1992 El Niño, J. Phys. Oceanogr., 27, 217-235.

Shchepetkin, A. F., and J. C. McWilliams (1998), Quasi-monotone advection schemes based on explicit locally adaptive dissipation, Mon. Weather Rev., 126, $1541-1580$.

Shchepetkin, A. F., and J. C. McWilliams (2003), A method for computing horizontal pressure-gradient force in an ocean model with a nonaligned vertical coordinate, J. Geophys. Res., 108(C3), 3090, doi:10.1029/ 2001JC001047.

Shchepetkin, A. F., and J. C. McWilliams (2005), The regional oceanic modeling system (ROMS): A split-explicit, free-surface, topographyfollowing-coordinate oceanic model, Ocean Modell., 9, 347-404.

Smith, W. H. F., and D. T. Sandwell (1997), Global seafloor topography from satellite altimetry and ship depth soundings, Science, 277, 19571962
Stammer, D. (1997), Global characteristics of ocean variability estimated from regional TOPEX/POSEIDON altimeter measurements, J. Phys. Oceanogr., 27, 1743-1769.

Stammer, D., and C. W. Boening (1992), Mesoscale variability in the Atlantic ocean from Geosat altimetry and WOCE high-resolution numerical modeling, J. Phys. Oceanogr., 22, 732-752.

Strub, P. T., J. M. Mesias, and C. James (1995), Altimeter observations of the Peru-Chile countercurrent, Geophys. Res. Lett., 22, 211-214.

Strub, P. T., J. M. Mesias, V. Montecino, J. Rutllant, and S. Salinas (1998), Coastal ocean circulation off western South America, in The Sea, vol. 11, edited by A. R. Robinson and K. H. Brink, pp. 273-314, John Wiley, Hoboken, N. J.

Sverdrup, H. U. (1947), Wind-driven currents in a baroclinic ocean; with application to the equatorial currents of the eastern Pacific, Proc. Natl. Acad. Sci. U.S.A., 33, 318-326.

Theiss, J. (2004), Equatorward energy cascade, critical latitude, and the predominance of cyclonic vortices in geostrophic turbulence, J. Phys. Oceanogr., 34, 1663-1678.

Tsuchiya, M. (1985), The subthermocline phosphate distribution and circulation in the far eastern equatorial Pacific Ocean, Deep Sea Res., 32, $299-313$.

Wyrtki, K. (1963), The horizontal and vertical field of motion in the Peru Current, Bull. Scripps Inst. Oceanogr., 8, 313-344.

Wyrtki, K. (1967), Circulation and water masses in the eastern equatorial Pacific Ocean, J. Oceanol. Limnol., 1, 117-147.

F. Colas, J. Pasapera, and J. Tam, Centro de Investigaciones en Modelaje Oceanographico y Biologico Pesquero, Instituto del Mar del Perú, Esquina Gamarra Y Gral., Valle S/N Chucuito, Callao - Lima, Perú.

V. Echevin and P. Penven, Institut de Recherche pour le Développement, 213 rue Lafayette, Paris, France. (pierrick.penven@ird.fr) 